Review Article

\title{
A Review on Structural Development of Magnetorheological Fluid Damper
}

\author{
Xianju Yuan (D), ${ }^{1,2}$ Tianyu Tian, ${ }^{1}$ Hongtao Ling, ${ }^{1}$ Tianyu Qiu, ${ }^{1}$ and Huanli He ${ }^{1,2}$ \\ ${ }^{1}$ School of Automotive Engineering, Hubei University of Automotive Technology, Shiyan 442002, China \\ ${ }^{2}$ Key Laboratory of Automotive Power Train and Electronics, Hubei University of Automotive Technology, Shiyan 442002, China \\ Correspondence should be addressed to Xianju Yuan; 349966565@qq.com
}

Received 19 October 2018; Revised 26 February 2019; Accepted 7 March 2019; Published 14 April 2019

Academic Editor: Alvaro Cunha

Copyright (c) 2019 Xianju Yuan et al. This is an open access article distributed under the Creative Commons Attribution License, which permits unrestricted use, distribution, and reproduction in any medium, provided the original work is properly cited.

Owing to unique advantages, magnetorheological fluid (MRF) dampers have been widely adopted in different fields of vibration control. Significant differences of structures occur in diverse fields due to the respective requirements, thus obtaining a large number of MR dampers. Having a good understanding of types, technical characteristics, comprehensive performance, and developing trend and their dependencies on structures are extremely conducive to innovative developments and a market selection. While the fundamental and partial structures are summarized in an existing review, the classification, latest technologies, and developing trend are not involved clearly. Therefore, the current survey aims at a comprehensive supplement in such aspects. The review begins with an introduction of the development, application, and classification. Then, details of three technical routes are revealed, and the development of each type is roughly analyzed. Finally, reflecting through this review, structures including a novel flow mode and miniature bypass valves have represented the currently structural and technical features. Fully considering the latest technologies and future requirements, the developing trend and a variety of applications will be anticipated.

\section{Introduction}

MR dampers which are known as damping elements have been developing rapidly since the 1990s of the last century. Of those, an MR damper had been developed and applied to a semiactive suspension system of a quarter car model in 1999 [1]. Also at the same period of the last century, MR dampers were manufactured by Lord, and these damping elements had been successfully applied to commercial vehicle seats and human prostheses [2]. In 2000, a singlecylinder damper was first designed and analyzed by the University of Maryland [3]. Utilized to control vibration of the suspension system of high-mobility multipurpose wheeled vehicle (HMMWV), another damper was created in the University of Nevada [4]. In 2001, a damper with maximum damping force of $300 \mathrm{kN}$ was provided by Tekki company, and its excellent effect had been reflected through vibration control in the National Museum of Emerging Science and Innovation [5]. An MR damper was also designed to control vibration of an artillery system in 2001
[6]. In 2002, adopting Delphi technology, another MR damper was included in the suspension of a passenger vehicle [2]. Hereafter, as one of the main damping components in the future, the MR damper has been considered widely in different vibration systems, and its development is expected to be very rapid.

In recent past 15 years, MR dampers have been widespread in different fields of vibration control $[7,8]$ including, but not limited to, the civil buildings and bridges [9-11], suspension systems in high-speed trains [12-14], advanced artificial limb system $[2,15]$, large washing machine $[16,17]$, automotive suspension systems [18-21], aircraft landing gear [22, 23], seats of commercial vehicle [24, 25], complex mechanical systems [26], helicopter rotor system [27], and so on.

The survey including the above literature would report that, although MR dampers have unique advantages such as continuous damping control, short response time, and large yield stress under smaller voltage [28-30], an available product in market is usually depended on a single coil [31] 
embedded in a piston groove. This structure brings obvious deficiencies in the effective damping channel, magnetic field utilization, adjustable damping range, versatility, manufacture and heat dissipation, etc. In order to overcome these defects and promote development of traditional MR dampers, almost all researchers have made great efforts to study the structures of MR damper and their influence on performance [31-101]. The improved ones mainly operated in such ways that change the number of coils in piston grooves [2, 34-41, 44, 46-48], adjust magnetic field by one or more permanent magnets [49-51], utilize double hydraulic system $[52,53]$, arrange a coil near the bottom or guide assembly [54-61], adopt one or more coils outside the outer wall of a cylinder $[45,62-64]$, transfer a coil to an external valve $[9,28,33,34,66,68-72,74-78,93]$, improve the magnetic circuit $[32,42,80,81]$, and design dampers with improvements in flow channels $[21,28,62,74-80$, 82-84, 86-101]. Of those, invented in the last few years, a damper with an external valve also adopted multistage radial flow mode is one of the latest structures [74-77], and another two dampers with multistage circumferential flow mode in miniature external valves can further promote the development of MR dampers [78, 79]. These improved structures, especially ones based on multistage circumferential flow mode and external valves $[78,79]$, have presented evident advantages such as longer damping channel, high magnetic field utilization, larger damping range, weak magnetic field excitation, smaller volume, lower energy consumption, better generality, and so on.

It is easily drawn from the above literature that $\mathrm{MR}$ dampers have been developed in the direction of highperformance products, and there are so many structures at this stage. A review entitled "Magnetorheological fluid dampers: A review on structure design and analysis" has presented fundamental structures. However, the classification, latest technologies, and developing trend are not involved clearly, especially not containing structure developed in the latest years. Therefore, this paper aims at a comprehensive review of representative structures and technologies. The following are details of existing ones.

\section{Improvements of Coil Number and Distribution}

\subsection{Coils Embedded in Piston Grooves}

2.1.1. Single-Coil Structure. The earliest MR damper usually depends on the magnetic excitation of a single coil. As is illustrated in Figure 1 [31], the coil is coaxially embedded in a piston groove of a single-tube MR damper. In this structure, soft magnetic materials with high permeability, low coercive force, and high magnetic saturation capability are usually adopted in the core and other magnetic components so that most of the magnetic flux will be passed through the effective channel $[32,33]$. The viscosity in the annular gap or a cylindrical hole can be adjusted by input current. Combining continuous damping control, simple structure, and relatively low cost, the damper is mainly utilized in suspension systems of passenger vehicles. However, the controllable annular gap or a cylindrical hole is mainly concentrated on the region perpendicular to the magnetic flux lines, and the viscosity of most channels is not adjusted.

The effective channel is very short, only a few millimeters in some dampers. Owing to a shorter damping channel, the damping force range is not particularly large, and larger damping force should not be considered by more turns because of size limitation and response time. Therefore, this damper is usually adopted in the field of small damping control, and its application is almost limited to automobile suspensions.

There is another distinctive single-tube MR damper with a single coil and two rods. Its principle of the magnetic circuit and adjustment of damping force are the same as those of the damper in Figure 2 [2]. This damper is usually applied for gun recoil applications, aseismic buildings, etc $[2,34]$. Although its larger size and force requirements can be realized by more coil turns as long as the response time is not too long, it is still used in a specific occasion because of the limited damping force range.

Of course, there are also existing structures with two tubes and a single coil. Owing to limitations of size, response time, and coil turns, the effective damping channel will not be very large whether a single-tube or two-tube structure is adopted. In addition to such a defect, a longer response time, coil heating, and trend of deterioration in damping behavior are also inevitable.

2.1.2. Multicoil Structure. In order to expand the effective channel, enlarge the controllable region of the magnetic field, increase the utilization of magnetic field, reduce inductance and response time, and so on, many scholars have adopted their best knowledge to develop MR dampers by two, three, and more coils [2, 35-41, 44-46]. Therefore, under a small current, a larger damping force may be achieved by a reasonable control strategy. Of those, a twintube damper with a two-coil structure, shown in Figure 3 $[2,34]$, usually includes an inner cylinder and an outer cylinder. The outer cylinder combines the functions of protecting inner components, storing MRF, and dissipating heat $[34,42]$. Located at the bottom of the inner cylinder, a foot valve assembly is used to regulate the flow between the MRF reservoir and the compression chamber [34]. In the compression stage, through an annular gap or cylindrical holes in piston, the fluid in the compression chamber first flows to the rebound chamber. The compression valve in foot valve assembly will be opened as long as its pressure difference is large enough, which will bring pressure hysteresis behavior in rebound chamber and hydraulic imbalance $[32,43]$. Combining such a deficiency, the relatively complex structure and weak dissipation will limit further development. Compared with a single-tube damper with one coil, this damper has some advantages such as larger damping force and range, especially a longer channel. The extended damping channel will expand application and reduce excitation current and energy consumption. However, owing to the limitation of size, stroke, and piston length, the arrangement of multicoils is very hard, and this damper is 


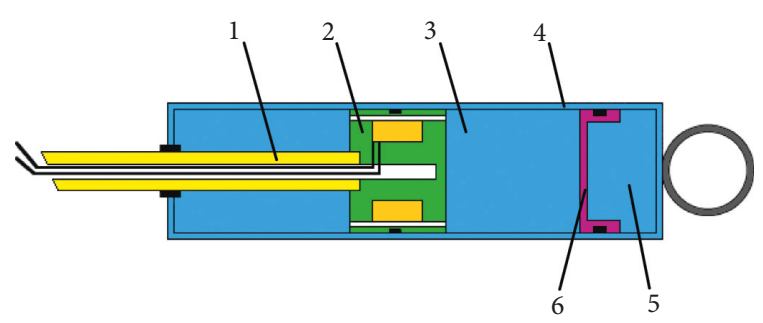

(a)

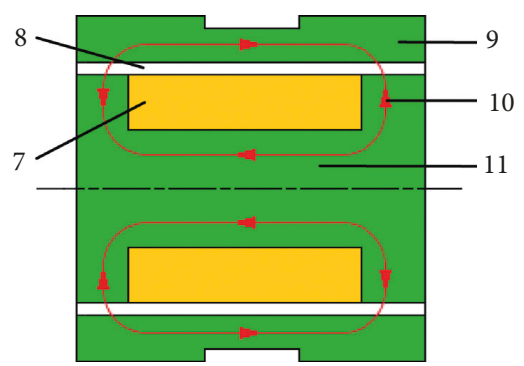

(b)

FIgURE 1: (a) Section view of a single-tube MR damper. (b) Magnetic circuit in a MR damper piston. 1, piston rod; 2, piston; 3, MRF reservoir; 4, housing; 5, compressed gas reservoir; 6, accumulator piston; 7, coil; 8, MRF gap; 9, iron sleeve; 10, flux; 11, core [31].

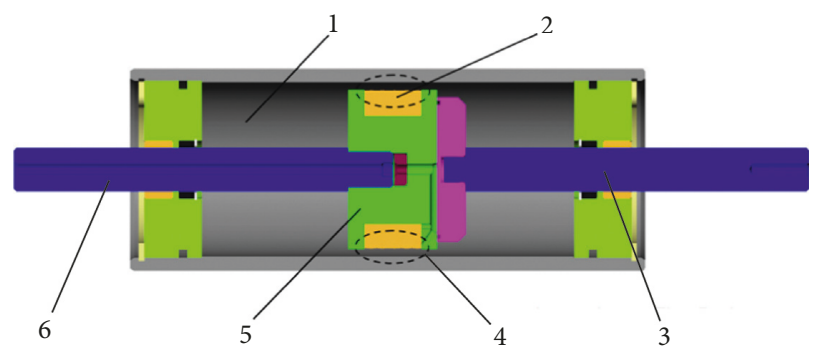

Figure 2: Double-ended MR damper. 1, MRF reservoir; 2, coil; 3, front piston rod; 4, approximate flux path; 5, piston; 6, rear piston rod [2].

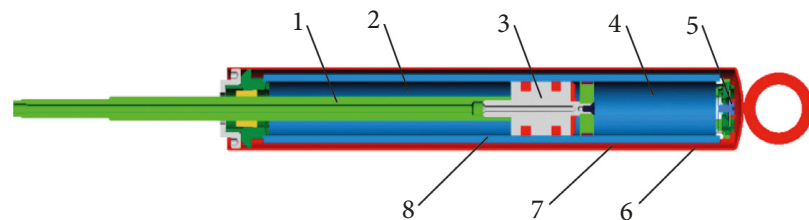

(a)

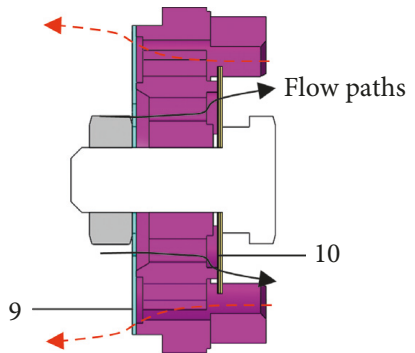

(b)

FIGURE 3: (a) Section view of a twin-tube MR damper. (b) Details of foot valve. 1, piston rod; 2, rebound chamber; 3, piston; 4, compression chamber; 5, foot valve assembly; 6 , outer housing; 7, MR fluid reservoir; 8 , inner housing; 9, return valve; 10, compression valve [2].

usually adopted in suspension systems of vehicles. It cannot be widely matched in different vehicles and other fields.

The multicoil structure including two coils have been widely studied by international scholars and applied in different fields [38-41, 44-46]. Another two-coil damper was suggested by $\mathrm{Hu}$ et al., and its maximum damping force is $1.21 \mathrm{kN}$ under the $1 \mathrm{~A}$ excitation current [38]. Of those, three coils are illustrated in Figure 4(b) [35, 47, 48]. In this structure, the length of the damping channel can be effectively extended. The another truth is that, in a damper with multicoils, the magnetic field intensity in the effective damping channel can be increased by the reverse winding of adjacent coils or through the reverse current on the coils of the same direction $[35,47,48]$. Therefore, the damping force needs to be further improved $[35,47,48]$. According to these principles, an MR damper with three coils had been developed by Lord and applied in an aseismatic building $[36,37,40]$. It is readily concluded from Figure $5[36,37]$ that the effective length is further extended because of four controllable regions in the damping channel [36, 37, 40]. The evident advantage of this structure can be reflected through maximum force of $20 \mathrm{kN}$ [36, 37, 40]. However, the length of wire, $1.5 \mathrm{~km}$ [40], must require larger volume and increase the inductance and cost. Its application will only be limited to the field of large damping control, and it will also not be widely matched in diverse fields. In 2007, adopting two rods, a three-coil structure was still considered in a MR damper, and it can be utilized in suspension systems of a train [39].

As is shown in Figure 6(a), a damper with four coils was proposed by Gavin et al. [44]. Without magnetic field, the minimum damping force is only $300 \mathrm{~N}$ [44]. Maximum one can be up to $4 \mathrm{kN}$ under $10 \mathrm{~A}$ current [44]. The controllable range is suitable for requirement of small damping control such as vehicle suspension. However, this damper brings two evident problems. One is the lower damping force, which is 


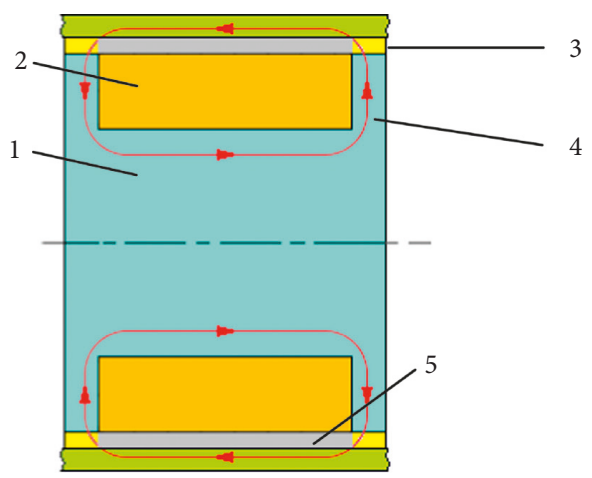

(a)

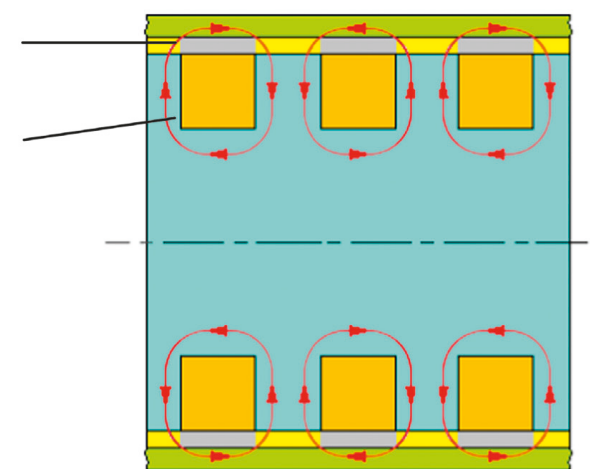

(b)

Figure 4: Difference of use between (a) single coil and (b) multiple coils with alternating polarity: 1, valve core; 2, coil; 3, activation area; 4, magnetic flux; 5, nonmagnetic section [35, 47, 48].

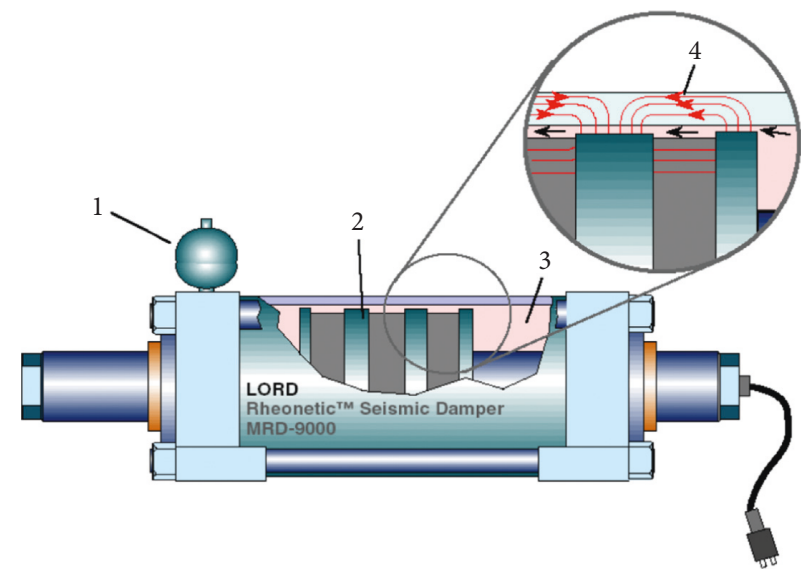

FIGURE 5: Schematic of $200 \mathrm{kN}$ seismic damper: 1, thermal expansion accumulator; 2, 3-stage piston; 3, MRF; 4, magnetic flux [36, 37].

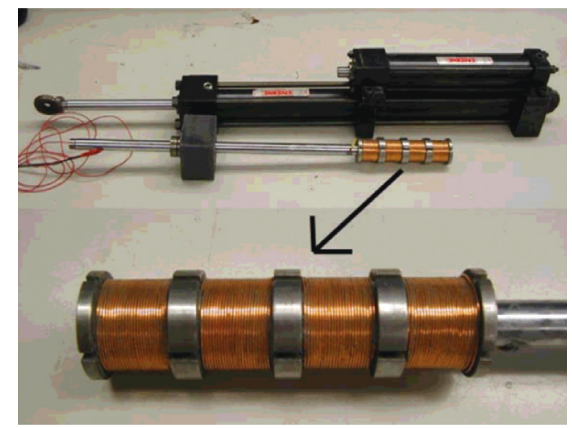

(a)

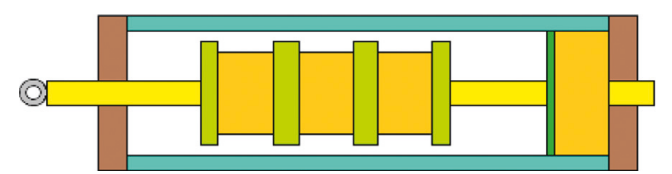

FIgure 6: (a) Multicoil MR damper [44] and (b) diagram of multiple-coil MR damper [48].

not consistent with the function of the multicoil structure. Other is the larger energy consumption. For example, maximum consumption will be hundreds of Watts since the resistance is at least a few ohms. Therefore, structural parameters of this damper should be further optimized.

For improving the structure mentioned by Gavin et al. [44], Yazid added an additional coil at the bottom so that the damper can work in the shear and squeeze modes, shown as Figure 6(b) [48]. Adopting a finite element method, structural parameters are successfully optimized, and damping characteristics are also further improved [48]. Developed by Zheng et al. in 2014, another damper with four coils was also operated in such a way that the coils were wound on the head of a piston [41]. The exciting currents of each coil are separate, and currents of adjacent coils were exactly opposite [41]. Combining appropriate parameters, maximum damping force of $17 \mathrm{kN}$ had been successfully achieved by these characteristics [41]. 
There are also existing structures with more coils, and damping force can be enlarged effectively. However, almost all of the multicoil structures increase sizes of pistons and reduce strokes of dampers. Manufacturing and processing are also difficult because of more complex structures and the arrangement of multiple coils in pistons. Especially, in order to enhance the damping effect, reverse currents on adjacent coils are necessary as long as the wound direction is unchanged [35]. This operated way requires multiple power supplies for the respective coils and increases energy consumption [35]. Such behaviors are not in conformity with requirements of the simpler structure and lower energy consumption [35]. Therefore, not requiring lower energy consumption, smaller sizes, and lower cost, some fields such as aseismatic buildings can utilize these dampers. Therefore, these dampers cannot be widely matched in different fields.

\subsubsection{Single-Coil or Two-Coil Structure with the Permanent} Magnet. Adopting one or two additional permanent magnets, another method is used to enlarge damping force by increasing magnetic field intensity rather than extending the length of a damping channel. Without magnetic field of coil excitation, certain yield stress of fluid will be first produced by permanent magnets [32, 49]. Owing to the better damping effect under no current, this structure is usually applied to a damping control system with failure protection $[32,49]$.

Therefore, these dampers still work normally when the original magnetic circuit system is damaged. An evident truth, in these structures, is the function of increasing or reducing damping force as long as a two-way driving device of current is matched with permanent magnets [32, 49]. The magnetic field intensity in the damping channel will be increased if the magnetic field generated by the coil is consistent with the direction of permanent magnets [32, 49]. Depending upon this principle, the larger damping force can be achieved under the smaller exciting current, and the utilization of the magnetic field is improved [32, 49]. Instead, magnetic field intensity in the damping channel can be reduced effectively if it is opposite to magnetic field of permanent magnets $[32,49]$. The minimum damping force can be further reduced $[32,49]$. Combining these characteristics, the range of damping force can be expanded to some extent $[32,49]$, and these dampers can be applied to more fields.

Considering the above advantages, Bose and Ehrlich proposed two types of dampers $[50,51]$. One is a single-coil structure with two permanent magnets, and the other is the two-coil structure combining one permanent magnet, which are shown in Figure 7. As is pictured in Figures 7(a)-7(c), in the first structure, two magnets are, respectively, arranged at the top and bottom ends of a coil. The directions of magnetic fields of magnets should be identical. A permanent magnet in the second damper is arranged between two coils, illustrated in Figures 7(d)-7(f). Portrayed in Figures 7(a) and $7(\mathrm{~d})$, the initial viscosity of the fluid near the permanent magnet is controlled by the magnetic field of a permanent magnet when the coil is out of energy. Therefore, a larger damping force can be produced without an unexcited magnetic field. In the adjacent area of a permanent magnet, the larger magnetic field intensity is essentially the result of the superposition of two kinds of magnetic flux as long as directions of two fields are identical, given by Figures 7(b) and 7(e). Oppositely shown in Figures 7(c) and 7(f), the magnetic field intensity will be decreased if the exciting current has been changed, which may bring smaller damping force. Therefore, damping force ranges of these dampers can be extended properly, especially expanding the maximum and minimum force simultaneously.

The structure mentioned in Figure $7[32,51]$ can be arranged in the piston ring groove and other parts. However, it is sometimes difficult to arrange them in a traditional piston, especially in a structure with more coils and permanent magnets. This difficulty can be overcome by concentric installation of the coil and magnet in a same groove. Representing this possibility, in 2010, a novel damper was proposed by Nehl and Alexandridis. As illustrated in Figure 8 [49], a coil and a permanent magnet are concentrically installed in a groove of the piston. The coil is mounted on the outer surface of the permanent magnet. A magnetic gap near the inner surface of the permanent magnet is helpful to reduce the leakage of the magnetic flux generated by a permanent magnet. Owing to the same principles mentioned in Figure 7 [32, 51], this damper also can be applied to fields with failure protection, and the range of damping force will be effectively expanded.

Of course, there may be three or more coil structures with several magnets if all of the parts can be installed. A truth is that, although the range of damping force will be properly expanded, the length of an effective damping channel and the controllable regions of the magnetic field cannot be extended obviously. Therefore, it is sometimes difficult to achieve a larger range of damping force, and the development of this structure is limited.

2.1.4. A Structure with Two Hydraulic Systems. Owing to a high cost of MRF, a damper with more MRF cannot be widely applied in many fields of vibration control. In order to obtain excellent performance and further reduce a cost, two hydraulic systems are adopted in some dampers. The active adjustment of MRF can be used to control flow of ordinary oil. According to this requirement, a damper was proposed by Koh [52]. As shown in Figure 9 [52], this damper includes two cylinders and two pistons. Two pistons are connected by a rod fixture. The MRF is arranged inside the inner cylinder, and another fluid is located in a region between the inner and outer cylinders. The first and second pistons are, respectively, installed inside the inner and outer cylinders. The number of damping channels in each piston is determined by the requirement of the maximum damping force. A coil is mounted on a groove of the second piston. The viscosity of MRF in channels of the second piston can be controlled when the coil is energised. The movement of the first piston can be influenced by that of the second one. Therefore, damping force of this damper can be adjusted actively, and a 


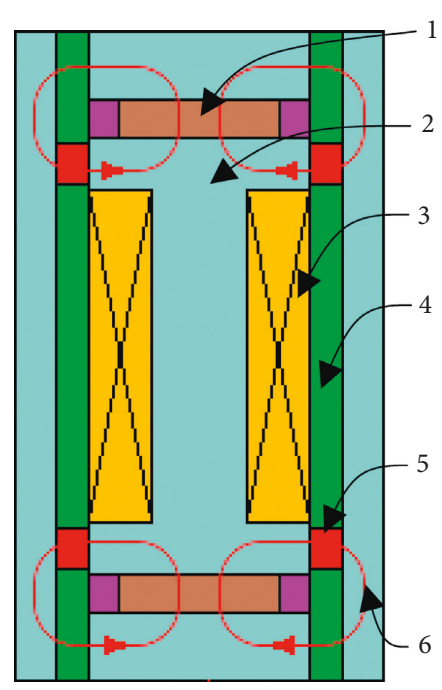

(a)

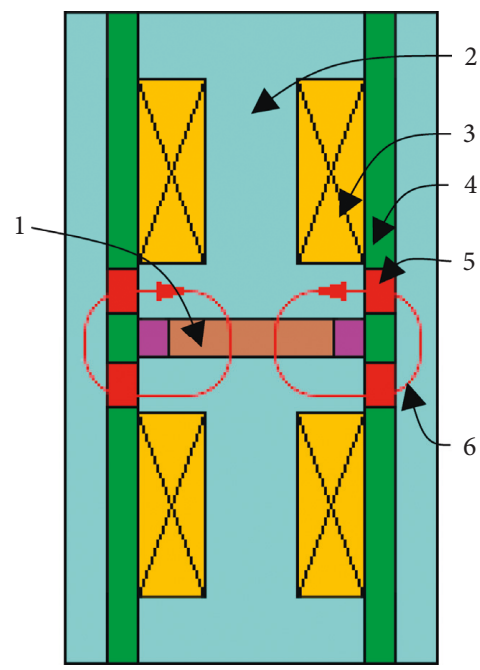

(d)

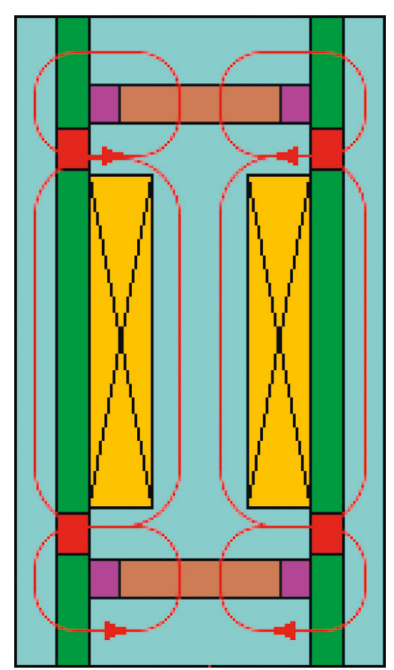

(b)

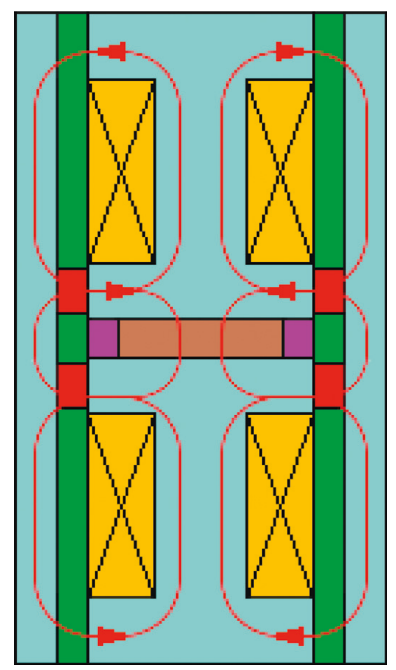

(e)

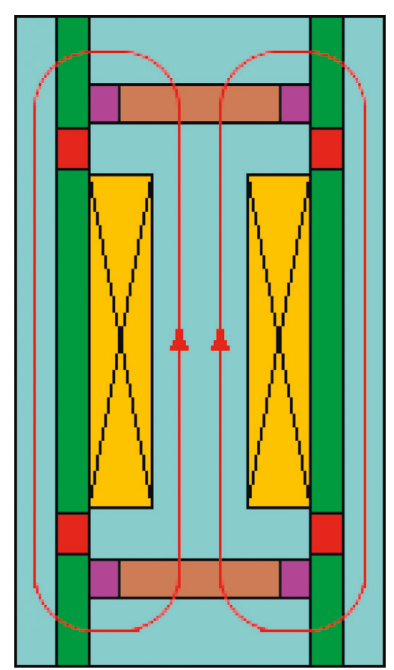

(c)

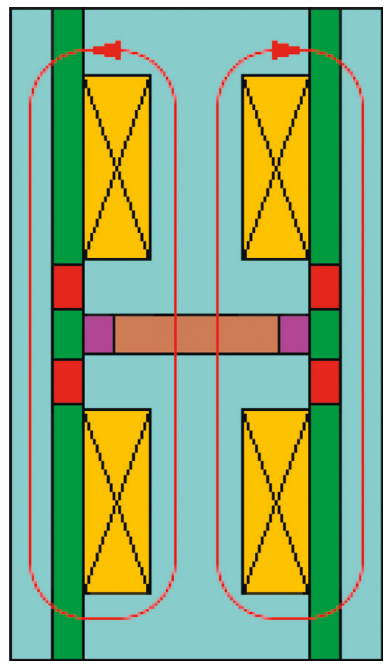

(f)

Figure 7: Single-coil and dual-coil fail-safe piston in three different operating modes: without coil current (a, d), with positive coil current (b, e), and with negative coil current (c, f). 1, permanent magnets; 2, core; 3, coil; 4, annular MRF gap; 5, MR valves; 6, magnetic flux lines $[32,51]$.

cost of it will be greatly reduced because of a small volume of MRF.

As is mentioned in Figure 10 [53], a damper with a similar structure had been developed by Jensen et al. Such a single-tube damper is divided into a three-chamber structure by two floating pistons. The movement of the first piston is limited to the first chamber, and another is in the second one. The ordinary oil, MRF, and high pressure gas are arranged in the first, second, and third chambers, respectively. A coil is located at a groove of the second piston so that MRF in the passageway can be actively controlled by the magnetic field. Owing to the adjustment to flow in the second chamber, the movement of the first piston will also be regulated effectively. Therefore, achieving an active adjustment of the damping force and a lower cost, this damper may be an excellent one in small or medium damping requirements.
Evidently, compared to a traditional damper mentioned in above sections, the high cost is successfully reduced. Adopting these dampers in a suspension system, appropriate damping force can be produced so that ride comfort can be improved to some extent. In this field, compared to a passive damper with ordinary oil, a relatively large damping range can be obtained. Owing to a short path of MRF and a similar structure of ordinary dampers, the switching time for damping force can be reduced, and the overall cost is also lower. However, still controlling the viscosity in an axial channel and arranging a coil in a piston, limitations of traditional MR dampers are not overcome.

Moreover, the flow channels of ordinary oil cannot be changed by a movement of MRF, and damping force is mainly controlled by MRF. More excellent performance may be obtained if MRF is used to adjust sizes of channels of ordinary oil. Usually, a squeeze mode of MRF is adopted to 


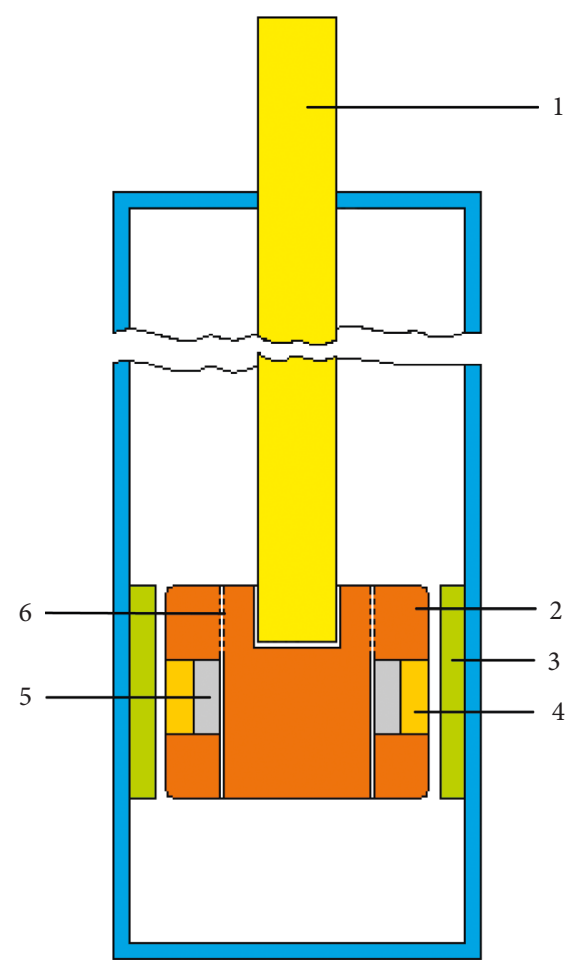

Figure 8: A longitudinal cross-sectional view of MR damper with permanent magnet: 1, rod; 2, piston; 3, flux ring; 4, coil; 5, permanent magnet; 6, magnetic gap [49].

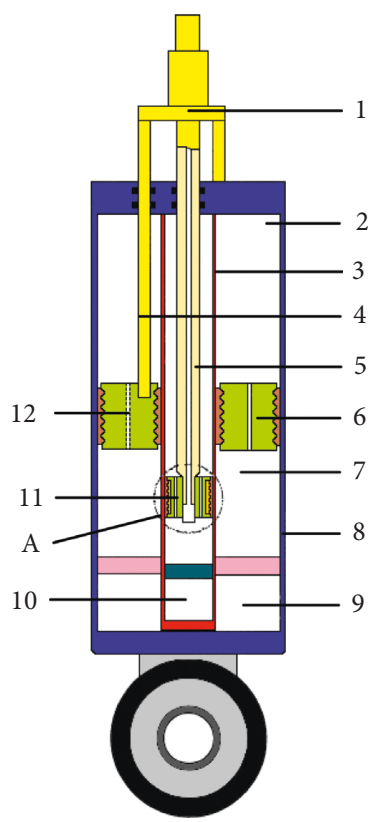

(a)

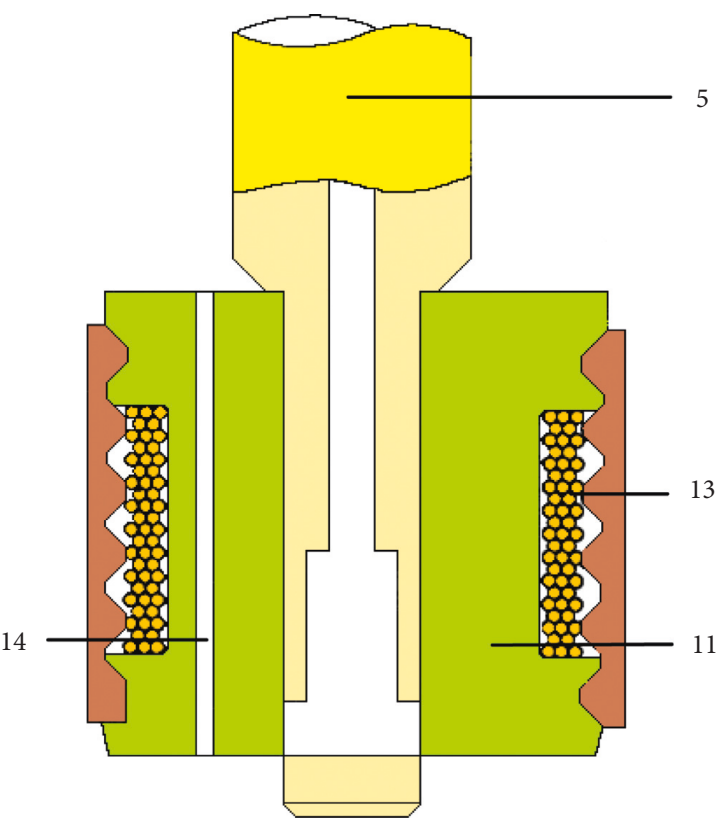

(b)

Figure 9: (a) A schematic cross-sectional view of a double-tube shock absorber using both MRF and an ordinary fluid. (b) An enlarged cross-sectional view of a portion "A" shown in Figure 9(a). 1, rod fixture; 2, first working chamber; 3, inner cylinder; 4, first piston rod; 5, second piston rod; 6 , first piston; 7 , second working chamber; 8 , outer cylinder; 9 , first accumulator; 10, second accumulator; 11 , second piston; 12, first orifices; 13, coil; 14, second orifices [52].

control sizes of the flow channel in another hydraulic system. In such a structure, the volume of MRF will be very small, thus almost achieving an equivalent cost of an ordinary damper.
There are other dampers adopting two hydraulic systems. Novel dampers with such a mode should be paid more attention, especially developing dampers combining new flow modes, bypass valves, and two hydraulic systems. 


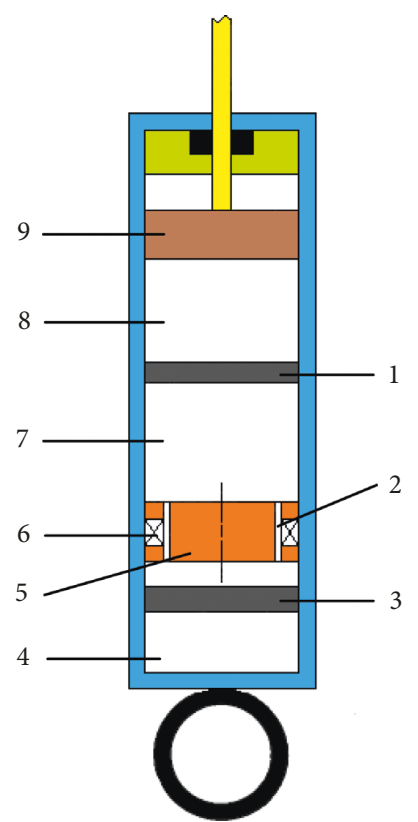

FIgURE 10: A longitudinal cross-sectional view of MR damper: 1, first floating piston; 2, passageway; 3 , second floating piston; 4, third chamber; 5 , second piston; 6 , electric coil; 7 , second chamber; 8, first chamber; 9, first piston [53].

Achieving excellent performance and a lower cost, MR dampers will be implemented in more fields of vibration control.

\subsection{Coils Located near the Bottom and Guide Assembly inside} Cylinder. As is mentioned in the above sections, it is relatively difficult to arrange coils in the grooves of a piston, especially installing coils in the axial direction of a two-tube damper. Therefore, located far away from a piston, a coil was first transferred to the bottom of the inner cylinder in 1994 [54]. Proposed by Carlson and Chrzan, flow between the inner chamber of the inner cylinder and the outer chamber can be controlled by a magnetic field, and an accumulator in the piston is also necessary [54].

Owing to the structure shown in Figure 11 [54], in a rebound stage, the fluid in the rebound chamber will be first flowed into the reservoir through openings. Via damping channels in the bottom end, the fluid in the reservoir is then flowed into the compression chamber [54]. Oppositely, during the compression stage, the fluid in the compression chamber will be first flowed into the reservoir through damping channels of the bottom end, and the fluid in the reservoir is then flowed into a rebound chamber [54]. In damping channels of the bottom end, the viscosity of fluid is controlled by the magnetic field whether the damper is in the stage of rebound or compression.

Following the same consideration, a further damper was first invented by Noakley in 2008 [55]. As shown in Figure 12(a) [55], this twin-tube damper includes a working chamber, an outer chamber, and a lower chamber. The working chamber is divided into the compression and rebound ones. The one-way valves are located at both piston

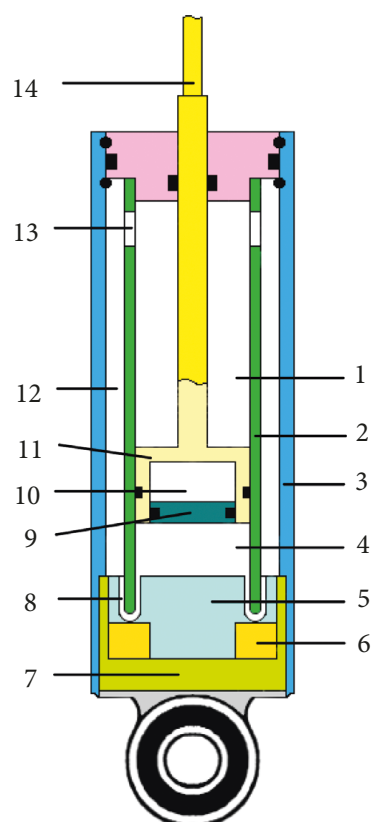

FIgURE 11: Twin-tube damper configuration with coil located stationary relative to the housing: 1 , rebound chamber; 2 , inner tube; 3 , outer tube; 4 , compression chamber; 5 , core element; 6 , coil; 7, cup-shaped end member; 8 , gap; 9, floating piston; 10, accumulator; 11, piston; 12 , reservoir; 13 , openings; 14 , piston head [54].

and foot valves so that the fluid can be flowed through a single direction. During the rebound stage, the one-way valve in a piston is closed and another one in the foot valve can be readily opened. Therefore, at this stage, the fluid in the rebound chamber will be flowed into the compression chamber through the inlet passage, outer chamber, passageways, lower chamber, and one-way valve in the foot valve. Oppositely, opening the one-way valve in a piston and closing another one in the foot valve, this damper ensures that fluid in the compression chamber will be first flowed into the rebound chamber through a one-way valve in the piston. The fluid in the rebound chamber is then flowed into the lower chamber through the inlet passage, outer chamber, and passageways. Resulting from such a way of flow, MRF must flow through the passageways. A coil is just arranged in a groove of the foot valve, and its magnetic field controls partial regions of passageways. Therefore, damping force in rebound or compression stage can be adjusted.

In addition to above characteristics, a compressed air chamber is also situated at the lower end of this damper. A movable baffle is designed to separate the compressed gas from MRF. The low gas pressure in the gas chamber effectively decreases static loads of the seal and bushing, thus reducing static friction. Usually generated by high-speed movement of a piston in the compression stage, a cavitation phenomenon can be successfully avoided by the one-way circulation of fluid. The heat dissipation is also better since the contacting area between the fluid and the outer cylinder is larger, which will greatly avoid attenuation of performance of MRF and prolong its service life. 


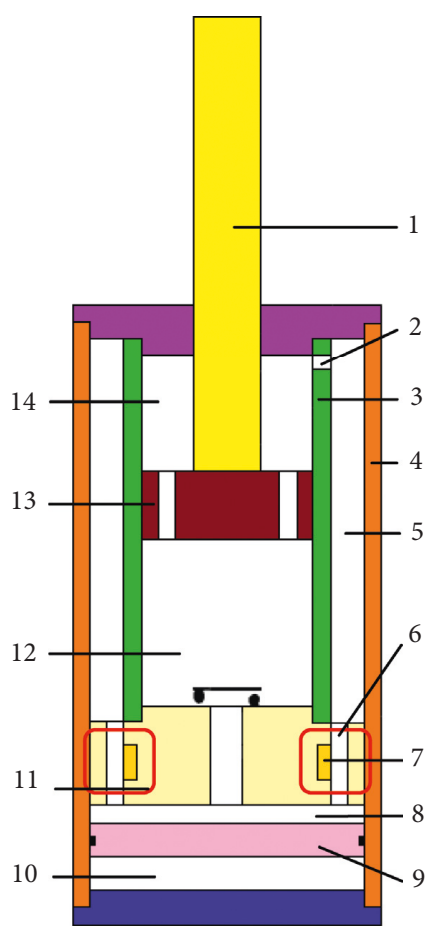

(a)

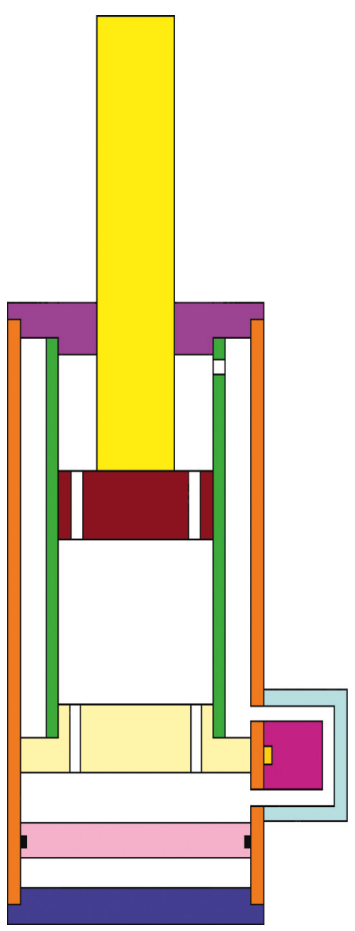

(b)

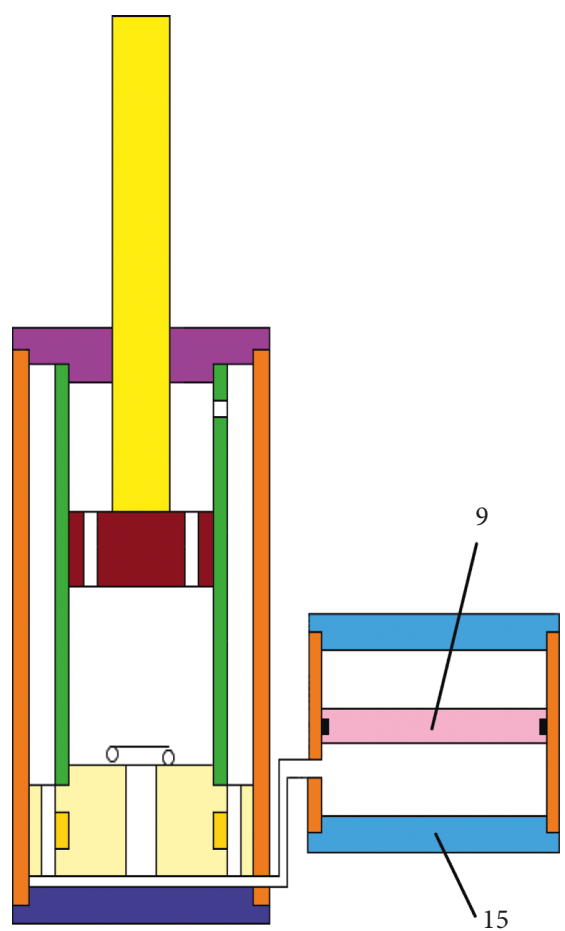

(c)

FIGURE 12: A schematic view of a twin-tube MR damper: (a) the coil arranged in a groove of the foot valve, (b) the side location of the MR valve, and (c) the gas chamber installed in an external valve. 1, piston rod; 2 , inlet passage; 3 , inner tube; 4 , outer tube; 5 , outer chamber; 6 , passageways; 7 , coil; 8 , lower chamber; 9 , moveable wall; 10 , gas chamber; 11 , foot valve (including lower one-way valve); 12 , compression chamber; 13, piston (including upper one-way valve); 14, rebound chamber; 15, reservoir [55].

Evidently, combining additional functions and controllable damping characteristics, this damper presents some advantages. However, it is very difficult to extend the effective length of damping channels, and the range of damping force is also very limited, which is almost consistent with those of a damper with a single coil or more coils in grooves of a piston.

According to the original structure in Figure 12(a) [55], two improvements are implemented, shown in Figures 12(b) [55] and 12(c) [55]. As is mentioned in Figure 12(b) [55], passageways have been transferred to the outside of the outer cylinder, and this damper can be classified into a type with an external valve. In Figure 12(c) [55], the gas chamber is installed in an external valve. The first and subsequent improvements can reduce axial lengths of dampers. However, radial width is also increased, which is not conducive to the arrangement of a damper in a limited space, especially in a suspension system of a passenger car. Moreover, owing to limitations of structure and size, such improvements cannot greatly extend effective damping channels, and extending the range of damping force as well as increasing the utilization ratio of the magnetic field is not perfectively achieved.

Including dampers shown in Figures 13 [56] and 14 $[57,58]$, there are many improved ones that can be divided into this type. In Figure 13 [56], a damper, the so-called

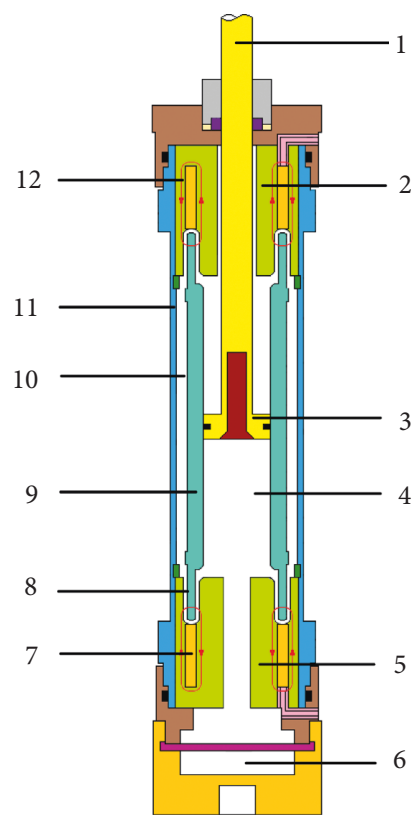

FIGURE 13: Schematic views of MRF damper with bifold configuration of electromagnet. 1 , piston rod; 2 , magnetic structure assembly; 3 , piston; 4 , inner chamber; 5 , magnetic end structure assembly; 6, pneumatic chamber; 7 , electrical coil; 8, cavity; 9 , inner tube; 10 , outer chamber; 11 , outer tube; 12 , flux return [56]. 


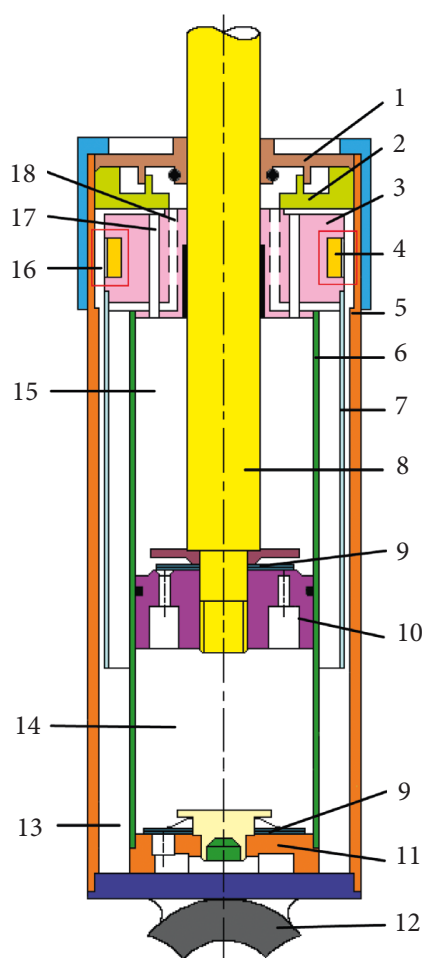

(a)

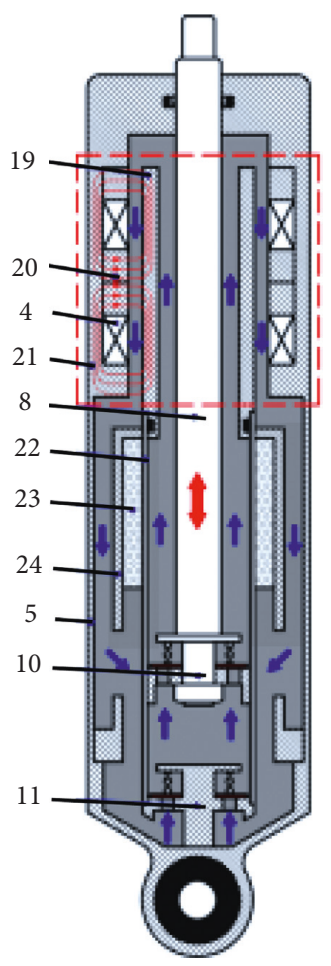

(b)

Figure 14: Schematic of pumping magnetorheological damper: (a) single-coil type [57]; (b) double-coil type [58]: 1, seal; 2, seal seat; 3, guide assembly; 4 , coil; 5 , outer cylinder; 6 , main cylinder; 7 , guide cover; 8 , piston rod; 9 , one-way valve; 10 , piston; 11 , foot valve; 12 , mounting bushing; 13, oil reservoir; 14, compression chamber; 15, rebound chamber; 16, active area; 17, pressure relief channels; 18 , reflux channels; 19, inner magnetic path; 20, middle magnetic path; 21, outer magnetic path; 22, inner cylinder; 23 , gas chamber; 24 , middle cylinder.

bifold valve damper, had been proposed by Mao et al. $[56,59]$. Different from the structure in Figure 12 [55], a coil is arranged at both ends of the inner cylinder, respectively. Combining the structure and arrangement of coils, a closed flux loop can be easily formed through the magnetic end structural assembly, inner tube and cavities, and magnetic lines pass through effective cavities perpendicularly. This two-coil structure ensures four effective regions controlled by a magnetic field, thus successfully extending the effective damping channels and improving utilization of the magnetic field $[60,61]$. There is no obvious space limitation in the arrangement of coils, and layout is more flexible. Not installing coils in a groove of a piston, this damper also brings very important features such as reducing the cross-sectional area of a piston head, decreasing area ratio between a piston and effective damping channels, limiting flow velocity of fluid in damping channels, generating smaller viscous force without the magnetic field, and expanding a damping range [56]. However, it is also very limited to extend effective damping channels, and it cannot be widely matched in different fields.

Proposed by Guo et al. [57], a coil is installed in the guide assembly of another damper. Combining pressure relief channels and reflux channels, such a structure is called a pump-type damper, shown in Figure 14(a) [57]. Through the outer cylinder, seal seat, controllable damping channels, and piston rod guide, the magnetic flux forms a closed loop. The one-way valves are also arranged in the piston and foot valve so that the continuous and unidirectional flow can be produced. An important truth is that, no matter whether the damper is in a state of compression or rebound, MRF must be first pumped from the bottom to the up. The fluid in a rebound chamber is then flowed through pressure relief channels, the active area, finally returning to the oil reservoir. Therefore, viscosity in active area where magnetic lines are just perpendicular to the direction of flow is controlled by the magnetic field.

In this structure, owing to the arrangement of the magnetic circuit system in a guide assembly, the number of coils and its layout will be more flexible. Considering this point and requirement of higher performance, an improved damper was proposed by Zhang et al., shown in Figure 14(b) [58]. Also according to a pumping-type principle, this damper adopts two coils with different winding directions, which can enhance the magnetic field intensity and expand the range of damping force.

The pump-type dampers as well as structures mentioned in Figure 11 [54], Figure 12 [55], and Figure 13 [56] will overcome difficulty in arranging coils in piston grooves, improve the utilization of the magnetic field, and not increase volume obviously. However, effective lengths of damping channels will not be expanded greatly, and larger damping ranges still cannot be only obtained by controllable currents. 
Therefore, these dampers are more suitable for vibration control of small or medium damping fields.

2.3. Coils Arranged on the Outer Wall of a Cylinder. Almost all dampers with coils inside cylinder bring difficulties in arrangement, heat dissipation, further improvement of damping behavior, and so on. In order to overcome such problems and improve performance, a coil is first arranged outside an outer tube. Also invented by Zhang et al., a damper of this type is mentioned in Figure 15 [62]. In this novel damper, spiralling passages are arranged in a guide assembly. The inlet and outlet are, respectively, located at the bottom and the top of the guide assembly. One or more spiralling passages can be mounted between the inlet and outlet.

In addition to additional advantages of heat dissipation and arrangement the power line, magnetic flux generated by coils passes through spiralling passages along the axial direction. The effective damping channels can be extended by further improvement of spiralling passages and more coils. However, owing to spiralling passages and axial flux, the flow direction is not completely perpendicular to magnetic flux, and the advantage of length will be reduced to some extent. Moreover, the effective length itself is limited in a guide assembly. There is a truth that, although larger damping force can be achieved by more turns and a large exciting current, this damper cannot overcome technical limitations of traditional MR dampers. Therefore, not achieving smaller current, weak magnetic field, and larger damping range, this damper is not a perfect one, and it is more suitable for vibration control of small damping fields such as vehicle suspensions.

Still controlling the viscosity in axial channels rather than spiralling passages, another damper was also developed by Guo et al., shown in Figure 16 [45]. As is portrayed in Figure 16(a) [45], the one-way flow can be produced by three tubes, one-way valves in the piston valve and foot valve. As shown in Figure 16(b) [45], two coils are arranged on the outer wall of the reservoir tube. The fluid in the active area is controlled by the magnetic field, which is consistent with the principle of a damper with a coil in a piston groove. Compared with traditional dampers, the regions controlled by the magnetic field will be extended effectively, and the range of damping force will be increased to some extent. Owing to one-way flow between the working chamber and the oil reservoir, the contact area of fluid is relatively larger so that good heat dissipation can be achieved. However, the controllable region is confined to the axial channel that is perpendicular to magnetic flux lines. Therefore, the effective length of the damping channel is still limited and the utilization ratio of magnetic field is still low, not removing the technical limitation of traditional MR dampers.

Following the same principle of viscosity adjustment in an axial channel, five coils are axially arranged in corresponding

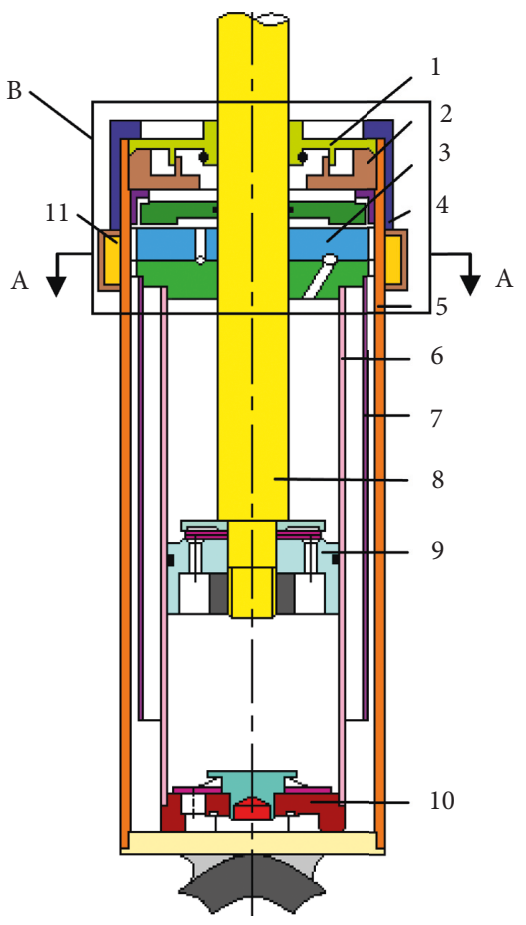

(a)

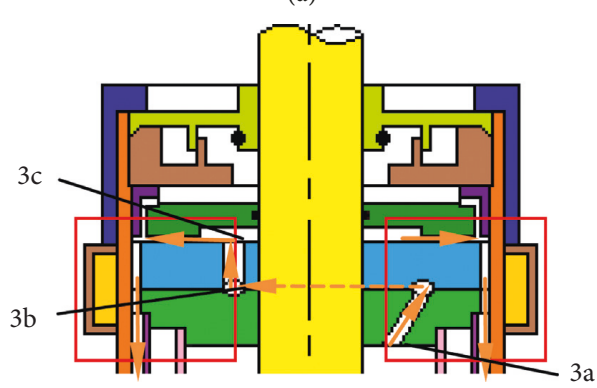

(b)

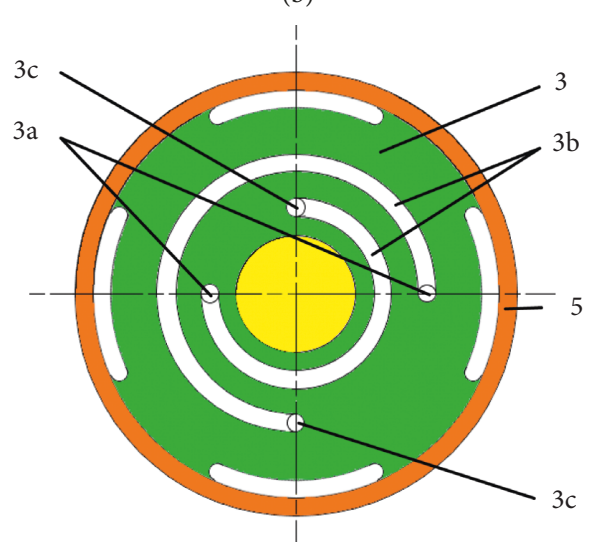

(c)

FIGURE 15: (a) Schematic view of MR damper with spiral valve. (b) Schematic view of the region enclosed by square in (a). (c) Cross-sectioned bottom view of the rod guide. 1, seal; 2 , seal seat; 3 , guide assembly; $3 \mathrm{a}$, inlet; $3 \mathrm{~b}$, spiralling passages; $3 \mathrm{c}$, outlet; 4 , end plate; 5 , outer tube; 6 , inner tube; 7 , dome; 8 , piston rod; 9 , piston; 10 , foot valve; 11 , coil [62]. 


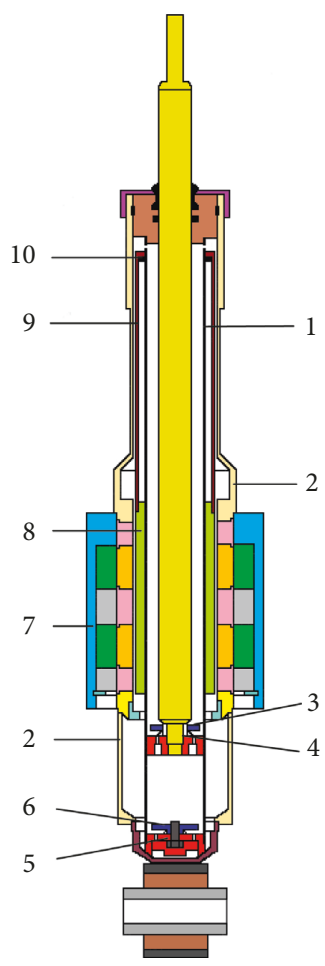

(a)

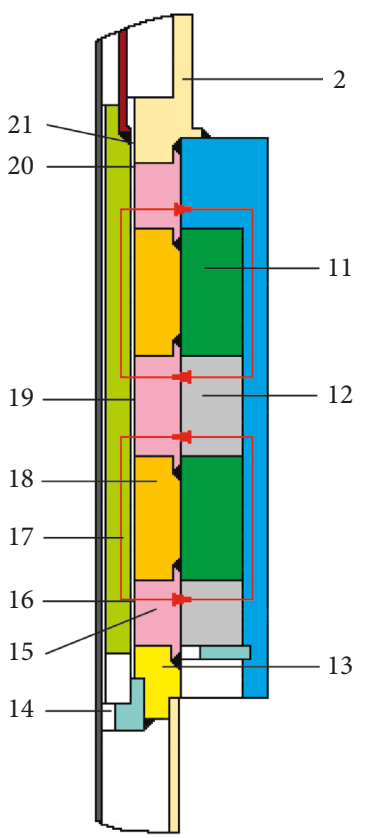

(b)
FIgURE 16: (a) Schematic configuration of multiple-coil MR damper. (b) An enlarged section view including magnetic flux and active area. 1, main cylinder; 2 , reservoir tube; 3 , check valve in the piston valve; 4 , piston valve; 5 , foot valve; 6 , check valve in the foot valve; 7 , outer tube; 8 , inner tube; 9 , accumulator; 10 , seal components; 11, coil; 12, magnetic guide ring I 13, retaining ring; 14, opening; 15, magnetic guide ring; 16 , active area I; 17, magnetic flux; 18 , nonmagnetic ring; 19 , active area II; 20, active area III; 21 , flow channel [45].

grooves of the outer wall of an inner cylinder, shown in Figure 17 [63, 64]. Evidently, partial regions that do not overlap with the height of coils are controlled by the magnetic field, and the effective length of damping channels is extended, which are very helpful to expand the range of damping force. The fluid must be flowed through the axial channel whether the damper is in the stage of compression or rebound. Moreover, compared to MR dampers with multistage coils winding on grooves of a piston, it is confident that this damper has obvious advantages in three aspects. First, under the same effective length of a damping channel, it has a longer stroke and an excellent ability to resist impact load [64]. Second, compared to the coils embedded in the piston groove, this damper can achieve lower off-state damping force and higher damping ratio by designing more suitable area of damping channels and a piston [64]. Third, in order to avoid arrangements of multicoil on a piston, the weight of a piston head can be reduced. However, in this structure, the arrangement of coils is still difficult, and the defects of the multicoil structure will be concentrated on it. In addition to the above behaviors, this damper brings other defects in heat dissipation, volume, and supply mode of currents.

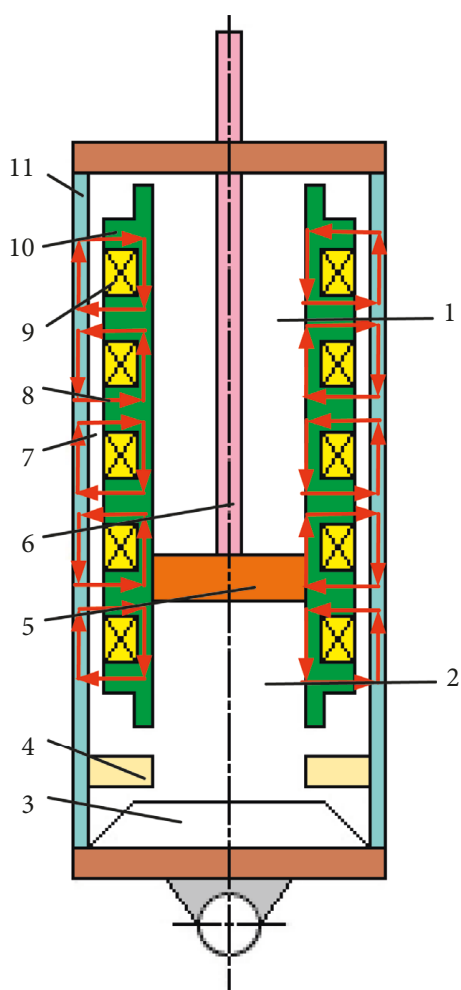

FIgURE 17: Schematic of MR damper with an inner bypass. 1, rebound chamber; 2, compression chamber; 3, accumulator; 4, connector; 5, piston; 6 , piston rod; 7 , MRF flow gap; 8 , magnetic flux line; 9 , electromagnetic coil winding; 10, bobbin (inner tube); 11 , outer tube $[63,64]$.

As mentioned in Figures 15-17 [45, 62-64], these dampers are relatively simple, and manufacturing is relatively easy. Especially in a structure with coils arranged on the outer wall of an outer cylinder, the heat produced by coils has little effect on the temperature of $\operatorname{MRF}[34,35]$. However, under the same size and coil turns, the response time of these dampers is relatively longer compared to a damper with a coil in a groove of a piston, and damping force is relatively smaller $[35,65]$. The leakage of magnetic flux is likewise larger [35]. Therefore, structural improvements in these dampers still cannot overcome the limitation of viscosity control in axial channels and bring new problems.

2.4. One or More Coils Installed in a Bypass Valve. The limitations, such as the arrangement, heat dissipation, volume, flexibility and scalability, etc, have been reflected through above structures more or less. Still adjusting the viscosity in an axial channel, a bypass valve outside the damper body is usually dealt with these problems. In these instances, an MR damper was first developed by Unsal $[33,34]$. Portrayed in Figure 18 [33], a coil is installed in a bypass valve. Through corresponding bypass ducts, two ends of a bypass valve are connected with chambers separated by a piston [34]. Two segments of axial channels near both sides of the coil are controlled by the magnetic field. 


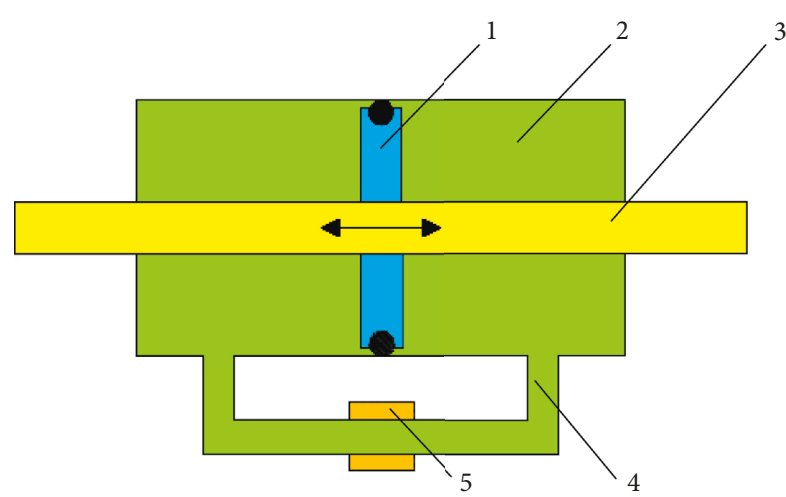

FIgURE 18: Schematic of bypass-type MR damper: 1, piston; 2, MRF; 3, shaft; 4, bypass duct; 5, coil [33].

In 2006, another damper with two rods was proposed by Hong et al., shown in Figure 19 [66]. An MR valve is embedded in a bypass duct connecting the corresponding chambers. The fluid must be flowed through axial channels outside a coil. The coil is situated in a groove of a component in the middle of the valve. Not overlapped with the coil, the regions at both ends of axial channels can be actively adjusted by the magnetic field, which is similar to that of a structure mentioned in Figure 18 [33]. Compared to the above damper, the main difference occurs in asymmetrical diameters of two rods. It is concluded from Hong that the damping and stiffness can be adjusted due to the active control of damping characteristics and the unequal diameters of two rods [34, 66]. Applying such a damper in suspension systems, vibration control and lightweight of vehicle can be achieved simultaneously [67]. Although this damper brings an additional function, the damping control in a limited axial channel has not yet been changed.

For obtaining larger damping force, two dampers with a different arrangement of the coil had been proposed by Nam and Park in 2007 [68]. As shown in Figure 20 [68], the axis of a coil is perpendicular to that of the damper, which is different from a parallel arrangement in most of MR dampers. Inside the coil, a channel parallel to the axis of the damper is controlled by the magnetic field. Almost the entire length is an effective one. The vertical passages near inner walls of the coil are also under control of the magnetic field. Therefore, damping channels and force can be effectively expanded owing to such arrangements in the coil and flow channels. Adopting such an arrangement, advantages of these dampers have been reflected through the application in fields with longer stroke and greater resistance to impact, such as artillery systems and aircraft landing gear systems $[34,68]$. In short, combining improvements in magnetic flux paths, flow channels, and a miniature valve, this damper can be serviced as an important development.

In order to get more excellent behaviors, new flow channels are usually adopted in MR dampers with an external valve. Among them, a special channel in a bypass valve was also developed by $\mathrm{Hu}$ et al. in 2007, shown in Figure 21 $[69,70]$. Mainly including a nonmagnetic stainless steel tube, a solenoid, and magnetic stainless steel spheres, the bypass

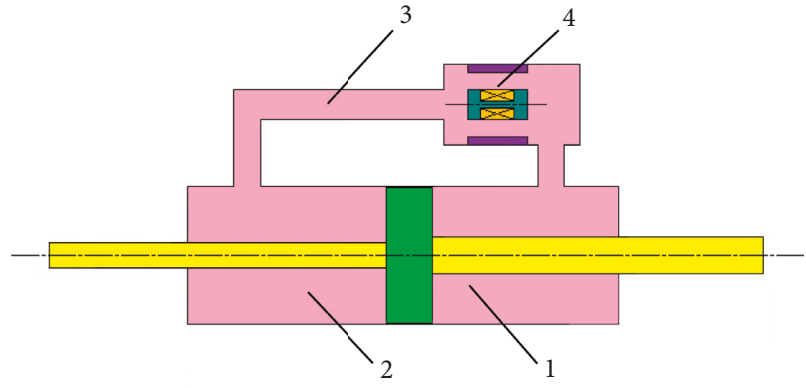

FIgURE 19: Hydromechanical model of the compressible magnetorheological strut: 1 , chamber $1 ; 2$, chamber $2 ; 3$, tubing; 4 , MR valve [66].

valve is connected with corresponding chambers through tubes $[69,70]$. The solenoid or a coil is coaxially arranged on the outer wall of a nonmagnetic stainless steel tube. These steel spheres are arranged inside the tube at random, and the magnetic flux lines generated by a solenoid will be passed through steel spheres axially. Unlike the original channels, MRF must be flowed through a path formed by spheres. Such a path is typically narrow, irregular, and tortuous. The yield stress and viscosity of MRF are regulated by a magnetic field, which is not parallel to the flow direction, thus producing the damping effect between both sides of an external valve.

Therefore, compared with original structures, adopting spheres or arranging other obstacles in an axial channel can obtain more excellent characteristics. Following the same consideration, three structures are proposed and analyzed by McLaughlin, shown in Figure 22 [71]. In an external valve, a coil is still located at the outer wall of a tube. Spiral channels are arranged inside axial channels of the first and second bypass valves, and a linear channel is adopted in the third one. Of those, magnetic steel beads with $2 \mathrm{~mm}$ diameter are also adopted in the second one, and $3 \mathrm{~mm}$ steel beads are arranged in the third one. McLaughlin has suggested that the porosity and tortuosity can be utilized to portray characteristics of three dampers. Depending on the study, a larger porosity and the smaller tortuosity are conducive to obtaining larger damping range in spiral channels. However, such parameters produce smaller equivalent damping force. In a bypass valve with spiral channels and beads, the features of the porosity and tortuosity are opposite to those of the damper only with spiral channels. The larger force will be generated, and the damping range is equal to that of the third one.

There are other existing dampers with improvements in axial channels of an external valve. Owing to the arrangement in a bypass valve, the manufacturing and maintenance are more convenient. The coil is almost not limited by an installation space, and the heat generated by the coil has little effect on MRF. Changing the structure of a bypass valve, the damper can be applied in different fields without other redesign, which significantly simplifies the development processes and reduces the cost of development. Usually, valves in the damper body are utilized so that the damper will be still operated in a passive mode if a bypass valve is in a state of failure $[9,34,72,73]$. However, an effective length of damping channels is still limited in a miniature bypass valve. 


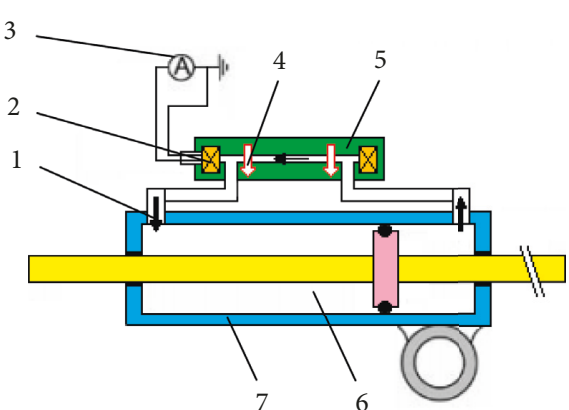

(a)

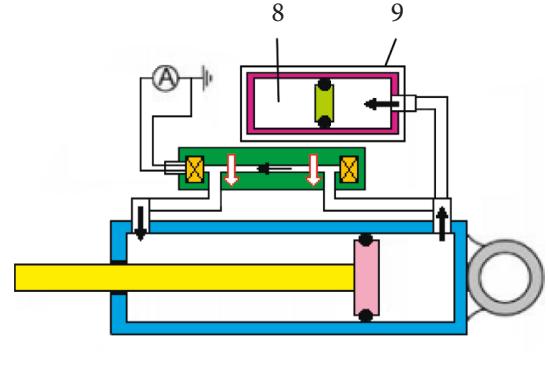

(b)

Figure 20: Schematic configurations of the proposed MR shock dampers: (a) double-ended MR shock damper and (b) single-ended MR shock damper. 1, MRF flow; 2, coil; 3, current source; 4, magnetic field; 5, MR valve; 6, MRF; 7, cylinder; 8, gas chamber; 9, piston-type accumulator [68].

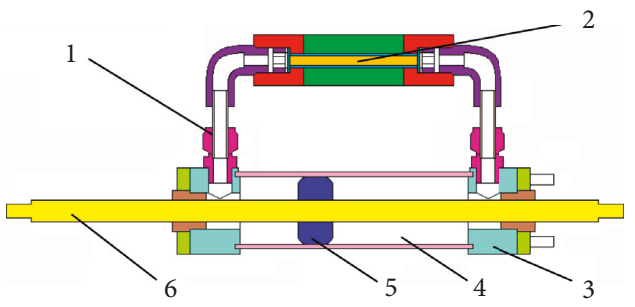

(a)

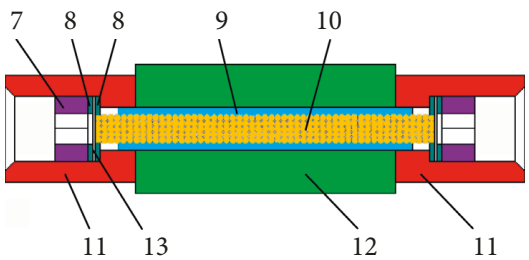

(b)

Figure 21: (a) Schematic configuration of the porous bypass-type MRF damper with external coil and (b) schematic of bypass valve. 1, tube and fittings; 2 , bypass valve; 3 , end block; 4 , MRF chamber; 5 , piston; 6 , rod; 7 , hollow set hex screw; 8 , nylon washer; 9 , nonmagnetic stainless steel tube; 10, magnetic stainless steel spheres; 11, steel end cap; 12, copper solenoid; 13, steel mesh [69, 70].

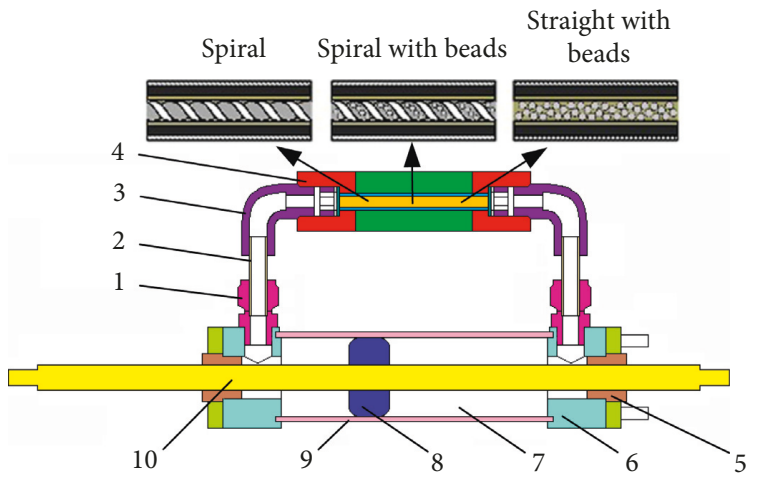

FIGURe 22: Bypass-type MR damper with external coil: 1, tube fitting adapter; 2, stainless steel tubing; 3 , tube fitting elbow; 4, bypass; 5 , seal; 6 , end block; 7 , MR fluid; 8 , piston head; 9 , piston casing; 10, damper shaft [71].

It is also difficult to arrange spiral channels and steel beads in a relatively small space. The large volume, an incompact structure, and the space restriction will be protruding problems if a larger bypass valve is adopted.

Overall, the wide damping range, large damping force, high utilization of magnetic field, small volume, low cost, scalability, low magnetic field intensity, low energy consumption, as well as others cannot be achieved completely. For further improving structure and characteristics in a bypass valve, novel flow modes such as the radial and circumferential flow modes are introduced. Combining such flow modes and external valves, representative structures will be illustrated in Section 4.

\section{Improvements of Magnetic Circuit}

Expanding controllable regions in an axial channel, the effective length of damping channel and magnetic field intensity in partial channels can be properly increased. Such a target can be also achieved by the improvement of the magnetic circuit. Of those, mentioned in Figure 4 [35, 47, 48], Figure 7 [32, 51], and Figure 8 [49], dampers with a multicoil structure and permanent magnets also can be classified into this type. Magnetic isolating elements are usually utilized to change paths of magnetic flux lines so that more channels can be controlled. Almost, magnetic field paths should be considered in all MR dampers. However, these cylindrical coils with a rectangular cross section are coaxially arranged on the outer wall of cylindrical elements. Such a coil and its arrangement do not contribute to further improving utilization of magnetic field and expanding a damping range.

Utilizing a special arrangement and other shapes of coils will obtain more controllable regions, which are different from functions of a multicoil structure, permanent magnets, and magnetic isolating elements. Of those, a damper with a new magnetic flux path had been developed by Sassi et al., mentioned in Figure 23 [42]. In such a new structure, the 


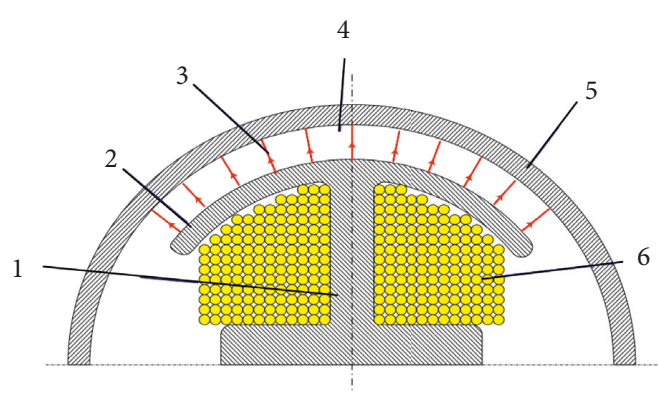

(a)

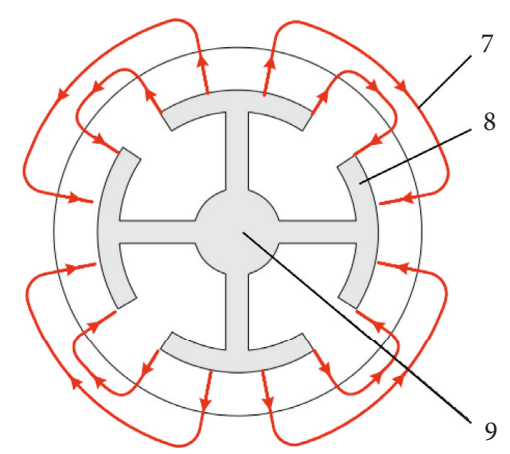

(b)

Figure 23: (a) Flux intensity and directions in new MR damper. (b) Flux intensity and directions for four magnetic poles configurations. 1, core; 2, shell; 3 , flux lines; 4, fluid gap; 5 , inner housing; 6, coil; 7, magnetic flux; 8 , magnetic poles; 9 , sheet core [42].

arrangement of coils is perpendicular to the axis of a damper, which is similar to that in a bypass valve [68]. Magnetic flux lines are radially passed through damping channels between the shell and the inner housing. In axial channels, the flow direction is perpendicular to magnetic flux lines. Almost, the entire length of damping channels is controlled by the magnetic field, which is obviously different from that of a traditional damper. Therefore, controllable regions are up to maximum under the limitation in sizes and axial channels, and utilization of the magnetic field is also higher. In addition to above advantages, the distribution of the magnetic field in the axial channel is likewise more uniform. The inductance of a coil and response time can be further reduced.

For further concentrating the magnetic field on the fluid gap and conducting magnetic flux, two pairs of magnetic poles are usually adopted in this structure, shown in Figure 23(b) [42]. It is verified from experiments that more excellent behaviors can be achieved by eight independent coils such as reducing current intensity, decreasing energy consumption, and optimizing in a wider frequency domain $[34,42]$.

However, the effective length of a damping channel is still limited because it is also determined by an axial channel type and sizes, and a special arrangement cannot break through the maximum axial length. Moreover, the complexity and difficulty in the arrangement are also increased.

In addition to a special arrangement of a coil, the effective damping channel can be expanded by changing the cross-sectional shape of a coil. The original coil with a rectangular cross section and a coaxial arrangement will limit the effective length of a damping channel since a region with the same height of a coil is almost not influenced by the magnetic field. A coil with a trapezoidal cross section can solve such a problem partially. For example, a damper with this coil was proposed by Nehl et al. [32, 81]. As illustrated in Figure $24[32,81]$, a trapezoidal coil is perpendicularly installed in a piston, and the partial width is embedded in the inner core. Owing to such a coil and the arrangement, a region with the same height of the coil will also be controlled by the magnetic field partially. Therefore, compared to an

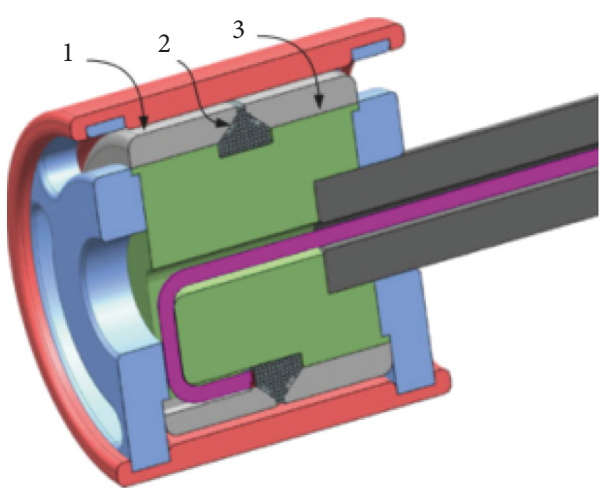

FIgURE 24: MR piston assembly with a trapezoidal coil: 1, poles; 2, coil; 3, inner core $[32,81]$.

original structure, this damper is a better one in view of effective channels and damping range.

However, these dampers including above two structures are limited to short axial channels. It is not possible to greatly expand damping range and apply them in wider fields of vibration control.

\section{Improvements of Damping Channels}

In addition to dampers mentioned in Figure 15 [62], Figure 20 [68], Figure $21[69,70]$, and Figure 22 [71], the position and number of coils in above structures as well as other existing structures are widely considered for improvement of damping characteristics, and flow channels and the magnetic circuit are not considered too much, which is one of the main methods for the adjusting damping range. There are other methods for adjusting damping characteristics. Of those, the number and shape of axial channels as well as other flow modes are one of the main methods for further development of MR dampers.

4.1. Structures with Asymmetrical Damping Force. Without additional flow channels and one-way valves, the viscosity of MRF is controlled in a rule axial gap or cylindrical holes, which will produce symmetrical damping force whether 
the damper is in a stage of rebound or compression. Such symmetry is not properly applied to some fields, especially not satisfying the requirement of vehicle stability and ride comfort. For suspension systems of a vehicle, a damping force in a rebound stage should be 2-3 times of compression damping force [82]. Therefore, for obtaining obvious asymmetry, a damper had been suggested by Oliver [82].

Shown in Figure 25 [82], a coil is still installed in a groove of a piston, and the difference of viscosity is adjusted in the first flow passageway, which is the same as those of traditional dampers. Unlike traditional ones, another valve assembly is coaxial arranged outside the controllable flow channel. Therefore, in the rebound stage, most of the fluid in a rebound chamber is flowed into the compression chamber through the controllable channel, and the viscosity in regions where the magnetic flux lines are perpendicular to them can be actively adjusted. Partial fluid is flowed to the compression chamber through outer notches of the orifice disc and second flow passageway. During a compression stage, the fluid will deflect spring and pass through the second flow passageway as long as force generated by the pressure difference at both ends of a piston exceeds the pretightening force of spring, which will reduce the compression damping force to some extent.

Actually, mainly adjusting viscosity in the first flow passageway, damping characteristic of a rebound stage can be achieved. Compression damping force is controlled by the viscosity in the first flow passageway and flow behavior of the valve assembly. Adjusting thickness of spacer, different damping characteristics will be obtained. However, the range of damping force is very limited, and it cannot be widely matched in different vehicles or fields.

In addition to this damper, many structures including Figure 14 [57, 58], Figure 15 [62], Figure 16 [45], and others adopt one-way valves or additional flow channels in piston valves and foot valves so that the asymmetrical characteristic of a damper can be obtained more or less. The related structures are shown in the previous or subsequent sections, and a summary will not be carried out.

With asymmetrical damping force, another damper is shown as Figure 26 [83]. In the improved damper, two coils are coaxially arranged in grooves of a piston. The viscosity is still controlled in the axial channel, and active adjustment of damping force is the same as that of a traditional damper. Significant variations in damping behavior occur as a result of tapered annular flow channels. Under the same flow rate or piston speed, the pressure drop from the wider section of the gap to the narrow section of the gap should be different from that of an opposite flow. Therefore, damping force of different working stages may be obviously different.

Although these dampers including other shapes of axial channels will produce asymmetrical damping force, the structure of damping channels must be redesigned for specific occasions. Moreover, there is no breakthrough in the technical limitations of the traditional structures, and the development and application should be very limited.

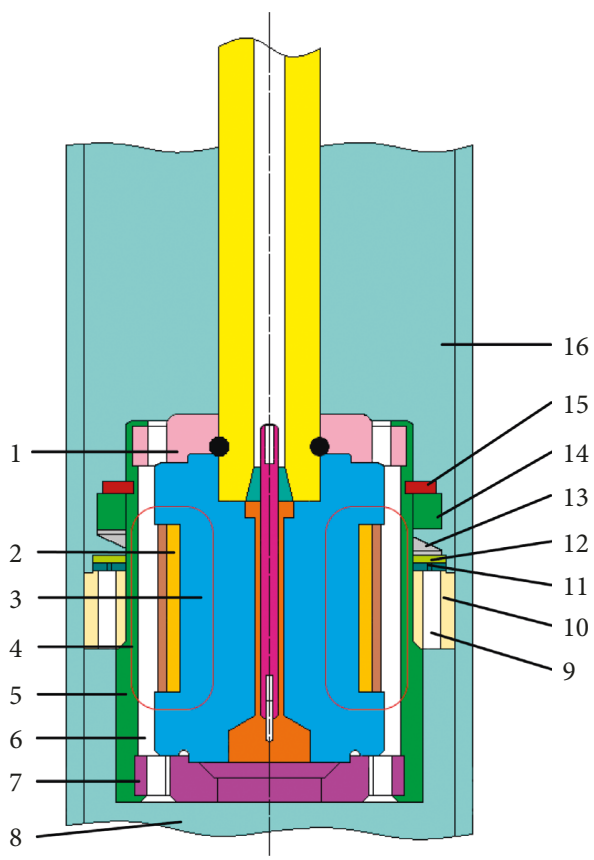

FIGURE 25: MR piston assembly with bypass valving: 1 , first end plate; 2 , coil; 3 , core; 4 , magnetic flux; 5 , shell; 6 , first flow passageway; 7 , second end plate; 8 , compression chamber; 9 , openings; 10 , valve seat; 11 , orifice disc; 12 , valve plate; 13 , spring; 14 , spacer; 15 , retaining ring; 16 , rebound chamber [82].

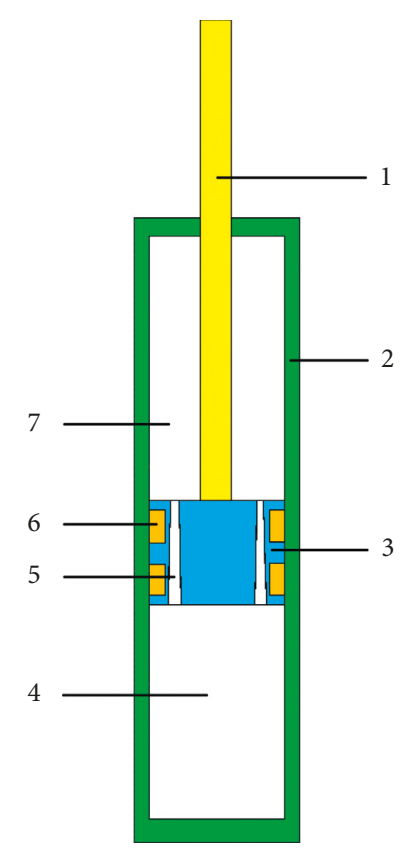

FIgURE 26: Schematic of the MR damper with tapered MR valve: 1, rod; 2 , cylinder; 3 , piston; 4 , compression chamber; 5 , tapered MR valve; 6 , coils; 7 , rebound chamber [83].

4.2. Additional Passageways without Magnetic Field. Not considering additional passageways and only controlling damping force in axial channels, a step damping force is present in a traditional damper, which reduces ride comfort $[84,85]$. The pressure may be suddenly fluctuated as a result 
of variations of exciting currents, thus bringing evident noise in a damper [86]. Under extreme conditions, the maximum yield stress will be obtained in an axial channel as long as a current is large enough. The abnormal operation of an MR damper will occur due to such a behavior [51].

For overcoming the above defects, passageways not controlled by magnetic fields are added in a damper, shown in Figure 27 [86]. The fluid in original channels is still controlled by the magnetic field or input currents. Free flow in bypass holes can be successfully achieved. The sudden fluctuation of pressure can be effectively reduced by such an additional flow. In low-velocity regions, the effect of the additional flow has been reflected through reducing the slope of the force-velocity curve, which effectively limits damping force at low speed and extends a damping ratio $[21,84,87]$. The maximum damping force is almost not influenced by the additional flow. Therefore, adopting this damper, a suspension system can further improve the ride comfort of a vehicle [21, 87].

4.3. More Channels Controlled by Magnetic Field. In order to improve damping characteristics of traditional dampers, two or more axial channels are arranged in a piston. Of those, portrayed in Figure 28 [88], a damper with three annular flow gaps had been developed by Namuduri et al. [88]. In addition to three annular gaps, three magnetic flux rings are coaxially installed in a piston. A magnetic isolation device, the so-called magnetic flux barrier, is installed in the first and second magnetic flux rings, respectively, so that the magnetic flux lines must be passed through all of the three channels. It is readily concluded that controllable regions can be evidently increased. Combining a special piston, the damping ratio of this damper may be greatly expanded, especially ensuring more excellent damping characteristics at low speed [88].

Another damper with two annular gaps was proposed by Bai et al., shown in Figure 29 [89]. In this special structure, a permanent magnet is installed in a region between the upper and lower inner cylinder. Generated by the permanent magnet, magnetic lines form a close loop through the bobbin core, inner annular gap, inner cylinder, outer annular gap, and magnetic flux return. The magnetic field produced by a coil will counteract that of the permanent magnet as long as the input current is negative, thus reducing the damping effect. Utilizing positive current, the magnetic field of annular gaps can be enhanced because of the superposition of two fields. Therefore, in a larger velocity-controllable range, the dynamic force range will be extended greatly, and the ability of mitigating shock and vibration may be further improved. A large damping force can be achieved even if the exciting field is invalid, thus ensuring normal operation of a damper [89]. Actually, this failure protection is a function of the permanent magnet, and it is the same as that of other dampers shown in Figure 7 [32, 51] and Figure 8 [49].

There may be other dampers with more annular gaps. All of these structures effectively expand controllable regions and increase ranges of damping force to some extent. However, the viscosity is adjusted in axial channels, and coils

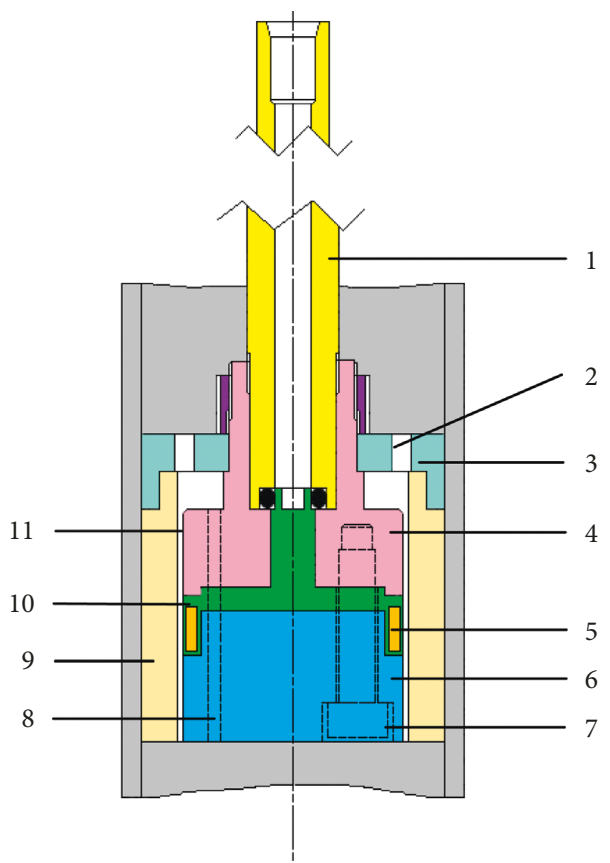

FIgURE 27: Cross-sectional view of a piston portion of a MR damper with bypass hole: 1 , piston rod; 2 , main holes; 3 , end part; 4 , the first core; 5 , electromagnetic coil; 6 , the second core; 7 , bolts; 8 , bypass hole; 9, flux ring; 10, coil assembly; 11, annular main clearance [86].

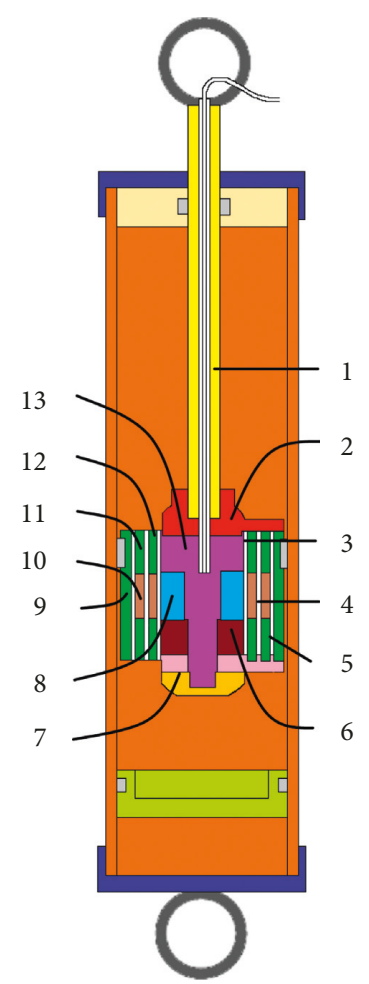

FIgURE 28: Cross-sectional view of MR damper including multiple flow gaps: 1, rod; 2, first end plate; 3, first annular flow gap; 4, second annular flow gap; 5 , third annular flow gap; 6 , pole pieces; 7 , second end plate; 8 , coil; 9, third flux rings; 10, magnetic flux barriers; 11, second flux rings; 12 , first flux rings; 13 , piston core [88]. 

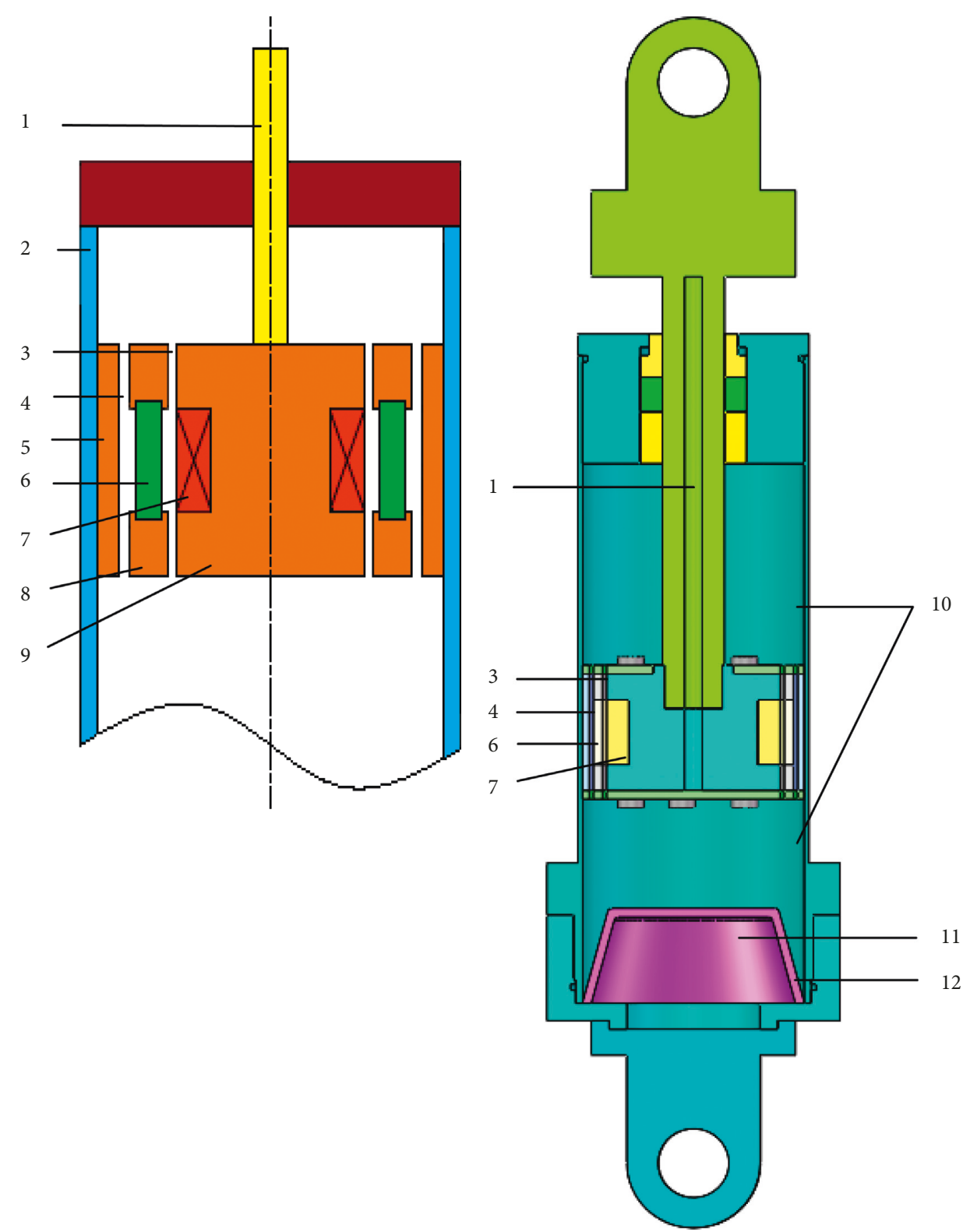

(a)

(b)

FiguRE 29: Schematic view of the bi-annular-gap magnetorheological energy absorber: (a) structural principle and (b) 3D drawing. 1, piston rod; 2, damper cylinder; 3, inner annular gap; 4, outer annular gap; 5, magnetic flux return; 6, permanent magnet; 7, electromagnetic coil winding; 8 , inner cylinder; 9 , bobbin core; 10 , MRF chamber; 11 , gas chamber; 12 , rubber accumulator [89].

are still installed in grooves of a piston, which will not overcome limitations such as the effective length of damping channels, utilization rate of magnetic field, maximum damping force, and damping ranges. Moreover, for expanding damping ratio, a large amount of optimization analysis for structural sizes is necessary and the development cost will be increased $[32,84]$. Therefore, these dampers are also transition products, and the progress is still limited.

4.4. An MR Damper with Bifold Flow Mode. Still controlling fluid viscosity in axial channels, an MR damper with bifold flow mode is reflected in Figure 30 [90]. An outer gap, inner gap, and feedback holes are arranged in a piston. The fluid in one side of the working chamber will be first flowed into an inner gap by holes in the piston cover, an outer gap, and a feedback hole. The fluid in the inner gap is then flowed to another side of the chamber through a feedback hole, an outer gap, and another hole in the piston cover.

First passing through the inner gap, outer gap, and outside of the piston, the magnetic flux lines are then formed closed loops by another outer gap, inner gap. Therefore, combining the flow path and the magnetic circuit, the fluid in feedback holes is not controlled by the magnetic field. Compared to a traditional damper, the effective length of damping channels and the utilized rate of magnetic field can 


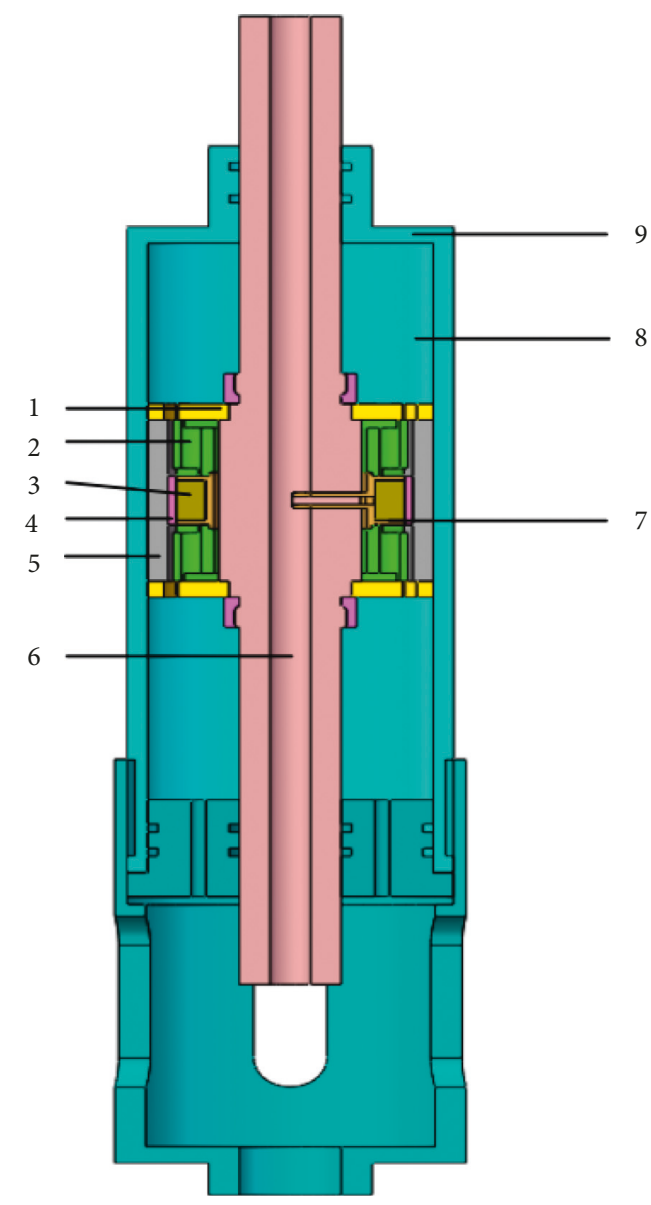

(a)

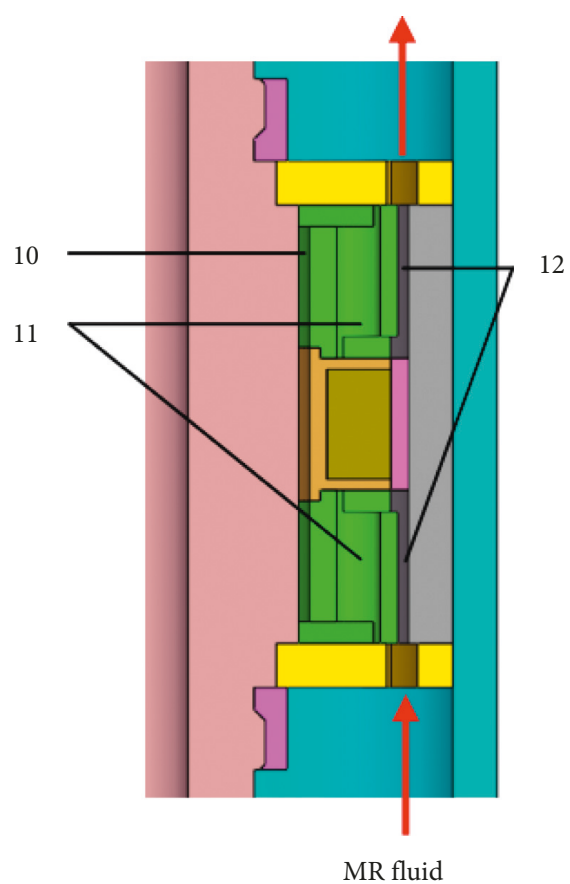

(b)

FIGURE 30: (a) 3D drawing of magnetorheological damper featuring bifold flow mode. (b) Flow channel of MR fluid. 1, piston cover; 2, magnetic core; 3 , coil; 4 , seal ring; 5 , outer piston; 6 , inner piston with rod; 7 , bobbin; 8 , MR fluid; 9 , damper housing; 10 , inner gap; 11 , feedback hole; 12, outer gap [90].

be enhanced. However, controllable regions are difficult to further expand, and the damping range is still limited. Moreover, although the structure is more compact, there are obvious difficulties in manufacture and heat dissipation, thus limiting its application.

4.5. Radial Channels Controlled by Magnetic Field. In addition to a structure mentioned in Figure 15 [62], the viscosity is adjusted in axial channels. Owing to controllable regions in axial gaps and limitation of sizes, the damping range, utilization rate of magnetic field, manufacture and heat dissipation, magnetic field intensity, energy consumption, and application fields are restricted, which are more or less reflected through dampers in the above sections as well as traditional ones.

Changing the axial flow mode can promote the development of MR dampers. As one of the innovations, the radial flow mode has been developed rapidly in recent 10 years. Of those, adopting a radial flow mode, a control valve in a damper is shown in Figure 31 [80]. Two composite passageways are symmetrically located at regions between the inlet and outlet, and each passageway is composed of two

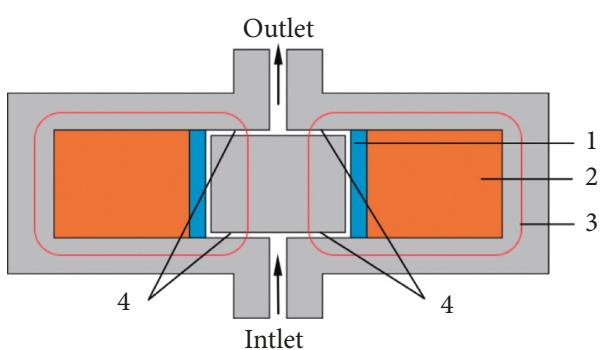

FIGURE 31: Cross-sectional view of MR valve with radial gap based on single-stage flow mode: 1 , magnetic isolation ring; 2 , magnetic coil; 3, magnetic flux; 4, radial gap [80].

radial channels and an axial channel. The fluid from the inlet is first divided into two parts, and each part is then flowed through the respective radial channel of the lower end, an axial channel, and the radial channel of the upper end. Finally, two parts of fluid from radial channels of the upper end return to the outlet. Achieving a separate flow and a converging flow, this damper is usually serviced as single-stage type.

Coaxially arranging a coil and a magnetic isolation ring in a groove ensures that most of the magnetic flux lines form 
closed paths through radial gaps. Combining the series of radial gaps, the effective length of a controllable channel can be expanded greatly. Owing to the long damping channels, the enough damping force is also produced even if the exciting current is suddenly interrupted, thus presenting normal operation of MR dampers. Utilizing single-stage or multistage structures can greatly expand the maximum damping force. Without magnetic field, a smaller damping force also can be achieved as long as the height or width of these channels is appropriately increased. Therefore, the damping range of these dampers can be very large. In addition to main advantages, the coil turns, magnetic field strength, excitation current, and energy consumption can be relatively reduced, and these dampers are more versatile in different fields.

Following similar principles, a damper with single-stage flow mode was also proposed by Aydar in 2010, shown in Figures 32(a) and 32(b) [91]. Unlike the structure mentioned in Figure 31 [80], two coils and a permanent magnet are adopted in this damper so that the magnetic field strength in radial channels can be further enhanced, thus expanding a damping ratio.

In fact, structures mentioned in Figures 31 [80] and 32 [91] can be arranged inside a damper or outside the body of a damper. The specific layout depends on other considerations such as the manufacture, heat dissipation, volume, cost, etc. For example, a controllable valve with three-stage radial mode had been proposed by Imaduddin et al., shown in Figure 33 [74-76]. For ensuring most of the magnetic flux lines through all of the radial gaps, the coil bobbin is magnetically insulated, and the core and casing are composed of high permeability materials. The small valve is arranged outside of the body of a damper, and the excellent damping characteristic is successfully obtained. However, the maximum force of this damper will not be very large because of limitation in sizes and stages. In order to obtain larger damping force, more stages can be adopted. Of those, arranging multistage radial gaps outside an inner cylinder, a damper with heavy damping force was developed by Liao et al. [92].

As is pictured in Figure 34 [92], sixteen inner annular baffles are coaxially arranged on the outer wall of an inner cylinder, and fifteen outer annular baffles are located at the inner wall of a middle cylinder. Resulting from such an alternate arrangement of baffles, two damping channels are determined. In each one, thirty-two radial channels are in series with thirty-one axial channels. An excitation coil is wound outside the outer wall of the middle cylinder, and its magnetic flux lines are perpendicularly passed through the fluid of all radial gaps, thus adjusting damping force of this damper [92]. In theory, most of the magnetic flux lines are passed through radial channels, and the utilized rate of the magnetic field is higher. Combining very long channels, the maximum damping force can be very large and the minimum one will be also relatively large. Therefore, adopting so many radial channels and a symmetrical structure, this damper is generally applied to vibration control of large damping requirement such as a high-speed train. In addition to above advantages, the magnetic field and input current will be weak as long as damping force requirement is not very large, thus further reducing coil turns and energy consumption. The application for different occasions will be achieved by a flexible arrangement of radial channels.

However, the arrangement of this damper also brings obvious difficulties in volume, coils, manufacture, and heat dissipation. In order to overcome such problems, an improved damper was also developed by Liao et al., shown in Figure 35 [77]. In this damper, a bypass valve with multistage radial flow mode is installed outside the body of a damper, and the inlet and the outlet are, respectively, connected with the compression chamber and the rebound chamber. The viscosity in radial channels is still regulated by magnetic field of a coil, and large damping effect can be obtained by a weak excitation current. At a given current of $0.7 \mathrm{~A}$, the damping force is up to $20 \mathrm{kN}$ [77]. Owing to the very large damping force and a weak current, the limitations in application and control sensitivity are still oblivious. Moreover, the nonlinear hysteresis phenomenon mentioned in the existing literature is very prominent. Although this damper may represent future trends because of the radial flow mode and a bypass valve, the damper based on radial flow mode needs more research and development.

It is readily concluded from the above two dampers that too many radial channels will greatly limit the application in different fields. Only adjusting currents, these dampers do not generate wide damping range from small damping effect to a very large one.

Still considering the advantages of a radial flow mode and a bypass valve, a damper in a suspension system of a high-speed train had been designed by Guo et al., shown in Figure $36[28,93]$. One-way valves in a piston and the foot valve are helpful to form a flow along a single direction. The fluid must flow through radial channels of the bypass valve whether the damper is in a stage of rebound or compression. A coil is arranged in the bypass valve, and the magnetic field of it determines a closed path through the magnetic guide cylinder, first magnetic guide plate, core, and second magnetic guide plate. Two regions between the magnetic guide plates and the core are controlled by the magnetic field. Therefore, flowing through the radial channels, the viscosity in them will be adjusted [93]. Only adopting onestage radial flow mode, this damper obtains relatively large damping force. The experimental results have demonstrated that the damping force is up to $9 \mathrm{kN}$ under an exciting current of $1.6 \mathrm{~A}$ [28].

There are other structures with radial flow channels. Almost all of these dampers bring significant improvements in expanding effective lengths of damping channels and enhancing utilization of magnetic field. The damping range can be expanded by increasing the overall length of radial channels and changing height of radial gaps. Especially, the damping range can be adjusted by different stages. However, too many radial channels and more stages will increase the volume, which will bring difficulty in a limited space. Combining to large damping force, these dampers are usually adopted in aseismatic buildings, trains, heavy machinery, bridge, etc. After sufficient optimization, it is possible to apply them in medium or small damping fields. According to the above 


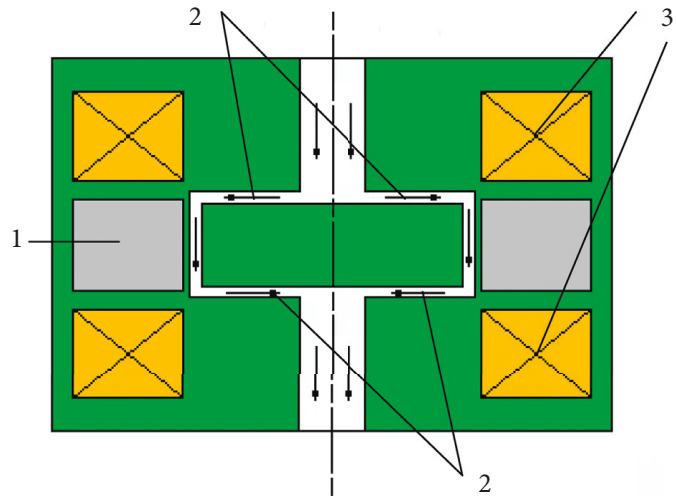

(a)

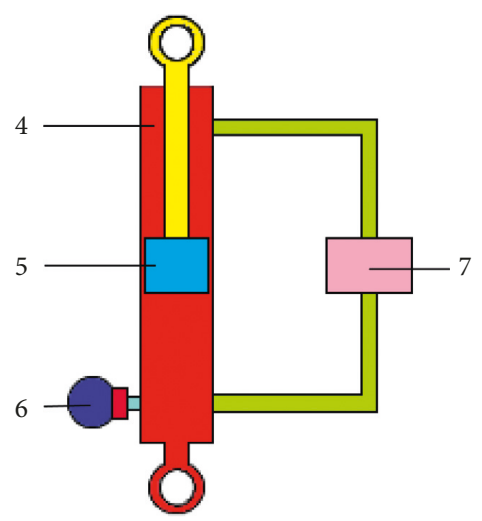

(b)

Figure 32: (a) Schematic of the two-way MR fluid damper. (b) Schematic view of the MR valve with the permanent-electromagnet system. 1, permanent magnet; 2, MRF valves; 3, electromagnets; 4, damper; 5, piston; 6, accumulator; 7, two-way MR fluid valve [91].

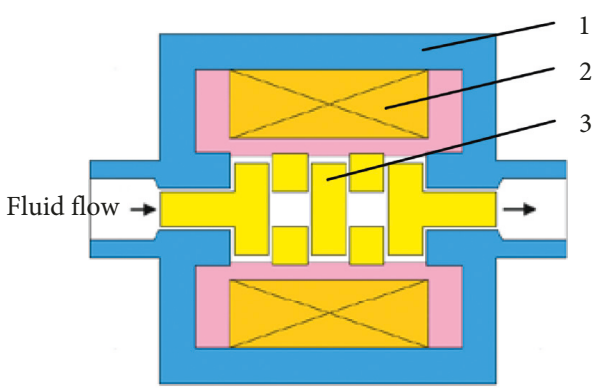

(a)

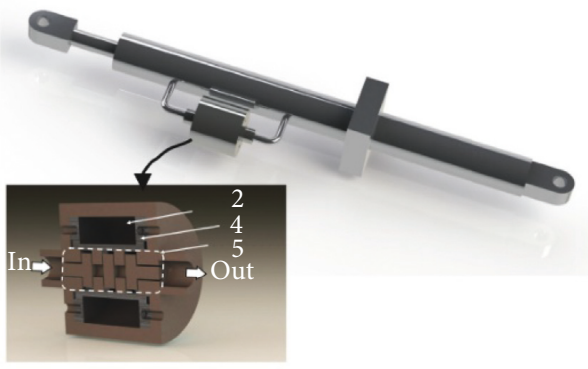

(b)

Figure 33: (a) Schematic view of the MR valve with a meandering flow path [74, 75]. (b) Photograph of bypass MR damper concept with meandering type valve. 1 , casing; 2 , electromagnet coil; 3 , core; 4 , coil bobbin; 5 , meandering path [76].

structures and others, combining a radial flow mode and a bypass valve, a damper can readily achieve the requirement of different damping range. The arrangement outside the body of a damper will bring other advantages such as the volume, cost, heat dissipation, flexibility, asymmetry, extendibility, energy consumption, etc. Therefore, a damper with radial flow mode in a bypass valve represents one of the future developments.

\subsection{Radial and Axial Channels Regulated by Magnetic Field.} As is mentioned in Section 4.5, the flow direction of axial channels is parallel to the magnetic flux lines. The fluid in axial channels is almost not influenced by the magnetic field. The controllable regions will be further expanded if the fluid in axial channels is also governed by the magnetic field. Achieving such a target, greater advantages will be concentrated on a damper such as further expanding damping force, reducing overall length of channels, limiting stages and volume, decreasing magnetic field intensity and input current, consuming less energy, etc.

Considering these advantages, a novel MR valve was first developed by Ai et al. [94]. As shown in Figure 37(a) [94], both axial and radial passages are under control of the magnetic field. Sufficiently optimizing currents, wire diameter, and structural parameters, an improved damper with more excellent behavior is shown in Figure 37(b) [95, 96]. Factly, shown in Figures 37(a) and 37(b), such an original structure and its optimized one have been utilized in the position of number 22 given in Figure 37(c). In 2009, Wang et al. [97] had verified that damping characteristics with two flow modes are evidently superior to those of one flow mode. The pressure drop in radial channels is greater than that of axial channels. This verification may serve as a basis for development.

Also following two flow modes, an MR valve inside a piston is shown in Figure 38 [98]. As shown in Figure 39(a) [99], a valve combining the radial and axial gaps was also proposed by Hu et al. [99]. The gap between the outer wall of a magnetic plate and the inner wall of the valve body is serviced as an axial channel, and another gap in series with the axial channel is a radial channel. The magnetic flux lines establish a closed path through the valve core, radial gaps, magnetic plate, axial gaps, and valve body, shown in Figure 39(b) [99]. Therefore, all of the radial and axial channels are controlled by the magnetic field. Factly, bypass valves of diverse dampers shown in Figures 32(b), 33(b), 35(a), 36(a), 37(c), and others can be replaced by this structure, and the damping characteristics will be improved.

The radial flow mode including two modes has presented great advantages such as a longer length of damping 


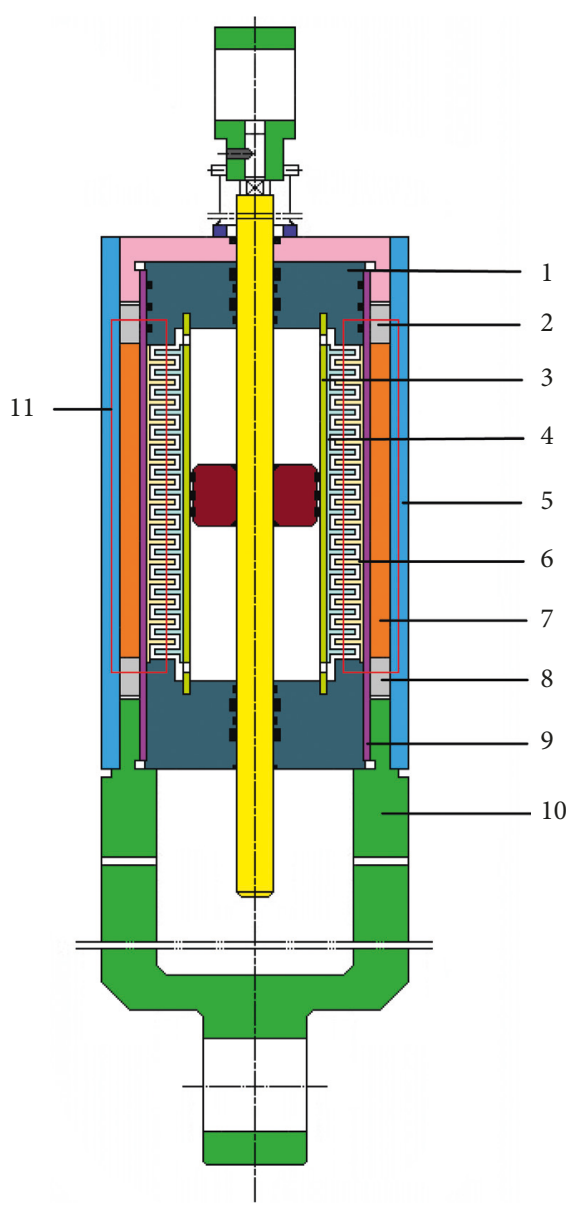

FIGURE 34: Schematic view of double-ended MR damper based on multistage radial flow mode: 1, upper cover; 2, first magnetic ring; 3, inner cylinder; 4, inner annular baffle; 5, outer cylinder; 6, outer annular baffle; 7, coil; 8, second magnetic ring; 9, middle cylinder; 10, lower cover; 11, magnetic flux lines [92].

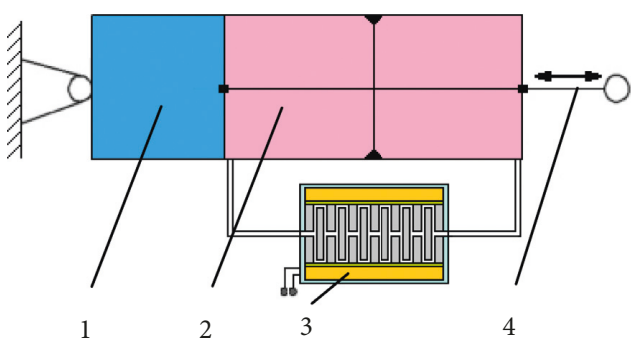

(a)

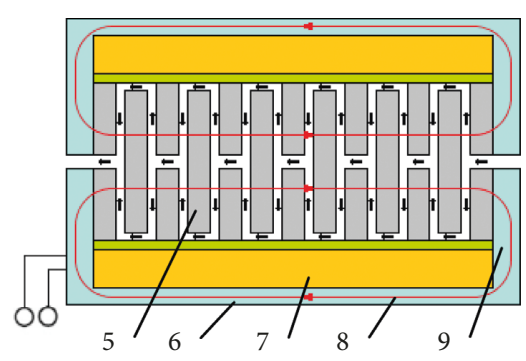

(b)

FIgUre 35: (a) Schematic view of bypass-type MR damper based on multistage radial flow mode. (b) Schematic view of MR valve. 1, hydraulic cylinder; 2 , MRF; 3, MR valve; 4 , piston rod; 5, core; 6 , steel cylinder; 7, coil; 8, magnetic flux line; 9, end cap [77].

channel and larger damping force. In order to benefit from such characteristics and apply them in different fields, an adjusted device for multistage channels is necessary. Depending on this requirement, adopting a modularized concept, a novel damper with an adjusted device was designed by Ichwan et al. [100]. Pictured in Figures 40(a)-40(c) [100], the structure and damping force of this damper can be changed by increasing or reducing the number of stages. The adjustment can be readily achieved by unscrewing the nut, changing stages of channels, and retightening the nut. The additional device and its regulated method will provide obvious advantages in the cost, maintenance, and application [100]. However, for avoiding the leakage of magnetic flux, a washer is usually installed in a region between two valves, which will lead to an inevitable air gap between two valve casings, thus affecting damping characteristics [100]. Moreover, for obtaining a specific path of the magnetic field, magnetic 


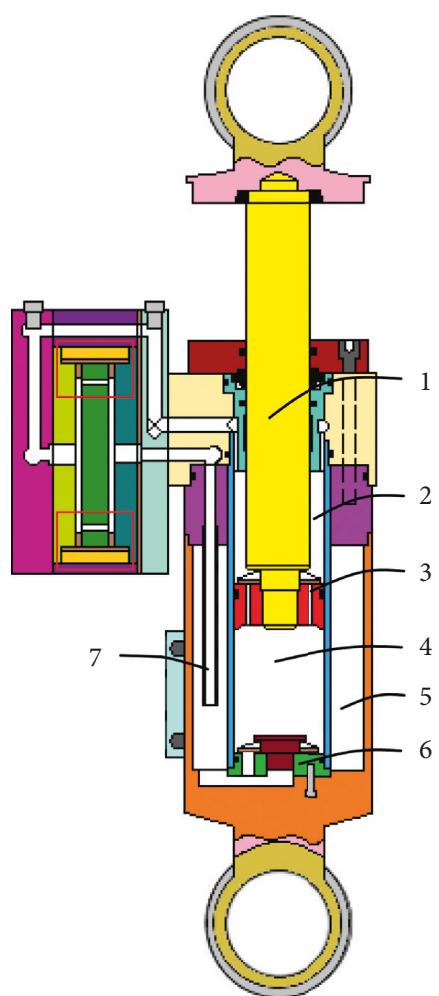

(a)

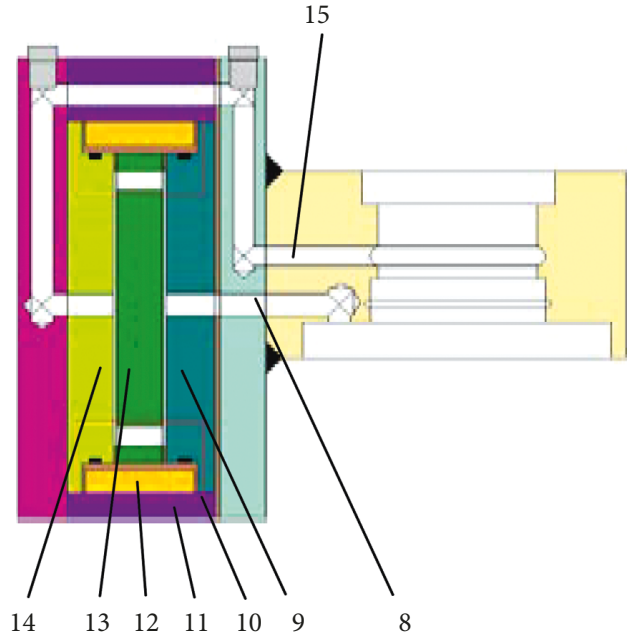

(b)

FIGURE 36: Schematic view of the twin-tube and bypass MR damper based on radial flow mode: 1, piston rod; 2, rebound chamber; 3, piston valve; 4, compression chamber; 5 , oil reservoir; 6 , foot valve; 7 , connecting tube; 8 , outlet; 9 , first magnetic guide plate; 10 , magnetic flux; 11 , magnetic guide cylinder; 12 , coil; 13 , core; 14 , second magnetic guide plate; 15 , inlet $[28,93]$.

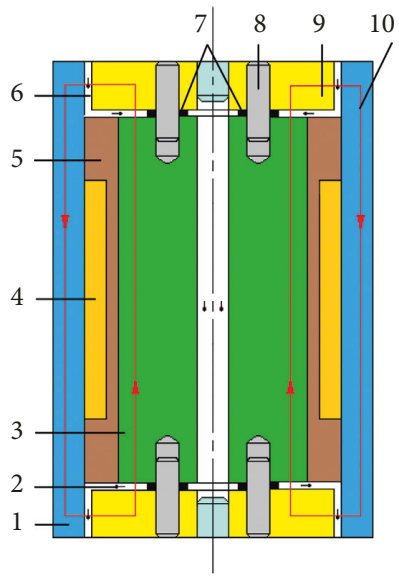

(a)

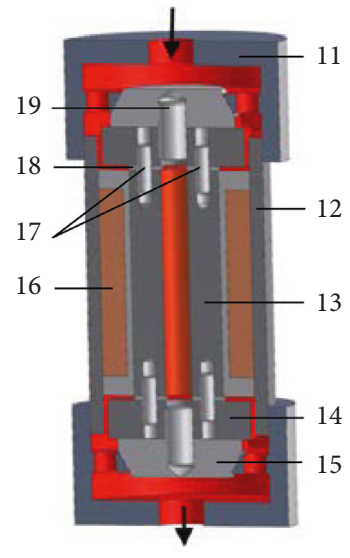

(b)

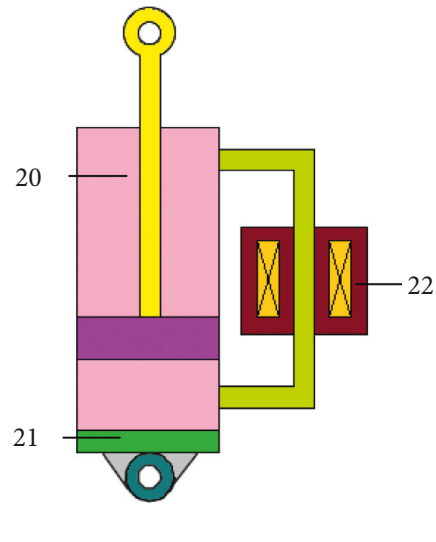

(c)

FiguRE 37: (a) The structure of an MR valve with annular and circular disk-type fluid flow resistance gaps [94]. (b) MR valve with both annular and radial flow path [95, 96]. (c) Schematic of an MR fluid damper [94]. 1, magnetic cylinder; 2, circular disk-type flow resistance gap; 3 , valve core; 4 , induction coil; 5, nonmagnetic bobbin; 6, annular flow resistance gap; 7, nonmagnetic washer; 8 , nonmagnetic pin; 9 , magnetic circular disk; 10, magnetic flux; 11, nonmagnetic head cover; 12, valve housing; 13, valve core; 14, magnetic disk; 15, cap; 16, coil; 17, nonmagnetic pin 1; 18, nonmagnetic washer; 19, nonmagnetic pin 2; 20, MR fluid; 21, accumulator; 22, controllable valve.

isolating elements are needed, further increasing difficulties in manufacturing and assembling.

In addition to above behaviors of these dampers, an uneven distribution of the magnetic field in different types of gaps is inevitable. The magnetic field intensity of a radial gap will be first saturated, and pressure drop of a radial channel is larger than that of an axial gap. For solving such an uneven phenomenon, establishing a serpentine-flux path of the magnetic field in axial channels, the improvement was achieved by Fatah et al. [80]. 


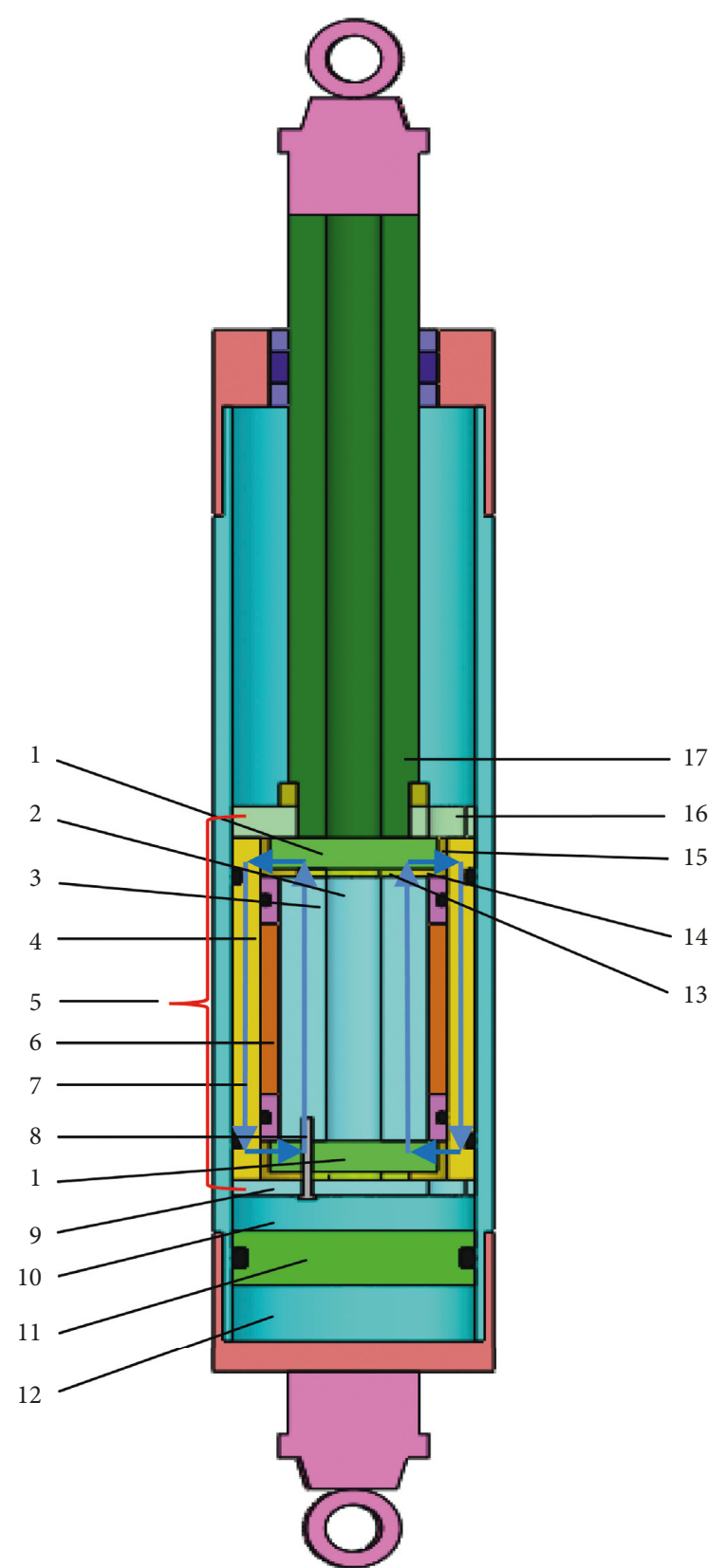

FIGURE 38: The 3D drawing of annular radial-duct MR damper: 1, circular disk; 2, central hole of core; 3 , core; 4, core cylinder; 5 , piston unit; 6 , exciting coil; 7 , magnetic flux; 8 , positioning pin; 9 , positioning disk; 10, MRF; 11, floating piston; 12, accumulator; 13, washer; 14, radial duct; 15, annular duct; 16, diversion hole; 17, piston rod [98].

The magnetic isolating elements, the so-called nonmagnetic rings, and disks are utilized to change the original paths of magnetic flux lines. According to different numbers of nonmagnetic rings and disks, the one-step serpentine-flux valve and two-step type are mentioned in Figures 41(a) and 41(b) [80]. Evidently, such a path increases the effective length of a damping channel and enhances the magnetic field intensity in the axial channel. The adjustment in radial gaps will be reduced, and the whole flux density will be further decreased because of a longer path. These characteristics will be more obvious with the increase of thickness of nonmagnetic rings [80]. Owing to its characteristics, such a structure can be utilized in pistons and bypass valves.

Overall, including two flow modes and magnetic isolating elements, the effective damping channels are expanded, and an uneven distribution of the magnetic field can be reduced to some extent. However, there are two negative aspects. One is the limitation in further improvement of damping force because of a long magnetic path or a larger thickness of rings. Other is difficulty in processing, filler, connection technology, cost, etc. Therefore, these structures, especially utilizing more-step serpentine-flux valve, should be considered according to the above factors.

4.7. Circumferential Channels Governed by Magnetic Field. Servicing as an innovative development, a circumferential flow mode is likewise proposed by Yuan [101]. In this mode, the fluid is flowed through one or more circumferential channels with a rectangular section. Almost all of the magnetic lines are just perpendicular to the flow direction in a circumferential channel. Theoretically, the distribution of magnetic field in a circumferential channel is almost uniform. The entire perimeter is an effective damping length. The effective damping channel can be greatly expanded even if a circumferential channel is not large, especially adopting multistage circumferential channels in series. Utilizing a damper with this flow mode, the maximum damping force can be very large. Only using a circumferential channel, a small damping force also can be obtained if height of a channel is increased properly. Owing to a long damping channel, the coil turns, excitation current, magnetic field intensity, and energy consumption can be further reduced if the damping requirement is not very large. Therefore, a damper with this mode can be widely matched in different fields of vibration control.

Following the above considerations, a damper in a suspension system of a vehicle is suggested by Yuan [101]. As is mentioned in Figure 42 [101], a coil is arranged on the outer wall of an outer tube, and three-stage circumferential channels are coaxially located at a region between the inner and outer tubes. An annular magnetic element, the so-called ferromagnetic core, is arranged on the upper and lower wall of a channel. A through-hole in a ferromagnetic core is in series with another hole in the wall of a channel. Shown as Figure 42(c) [101], in a rebound stage, the fluid in a rebound chamber is flowed into the first circumferential channel through the corresponding holes. The fluid from the upper hole of the channel is then divided into two parts. Each one will be delivered to the lower hole of the channel along the respective semi-circumference. Further flowing through the second- and third-stage channels, the fluid is successfully returned to a compression chamber. Under a compression stage, the flow direction is opposite and the principle is the same as that of a rebound stage. Combining the magnetic flux path mentioned in Figure 42(b) [101], a very large damping force can be obtained, and the utilized rate of the 


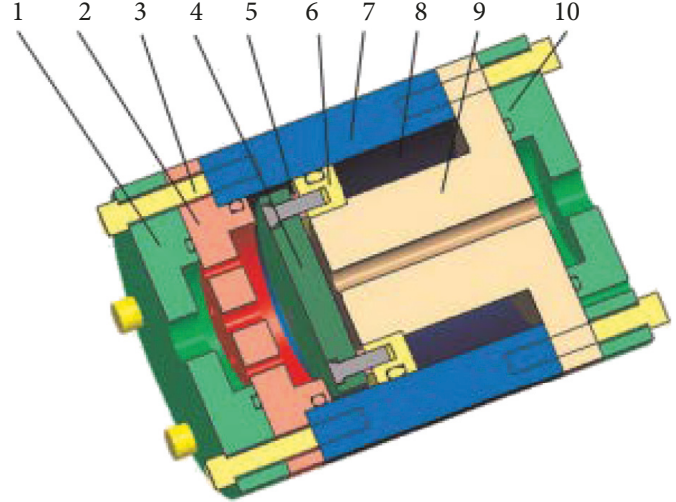

(a)

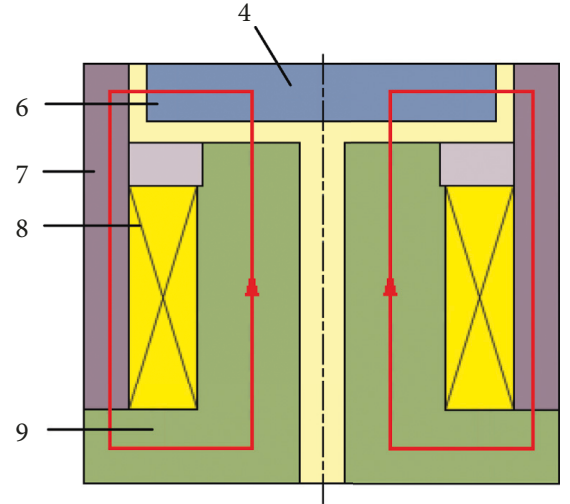

(b)

FIgURE 39: (a) Configuration of the MR valve. (b) The simplified magnetic circuit of the proposed MR valve. 1, left head cover; 2 , flow-guided plate; 3, screw; 4, magnetic plate; 5 , washer; 6, fixed plate; 7, valve body; 8, excitation coil; 9, valve core; 10 right head cover [99].

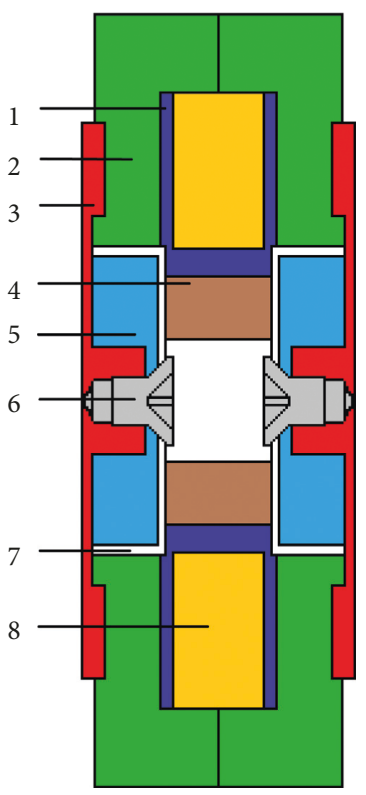

(a)

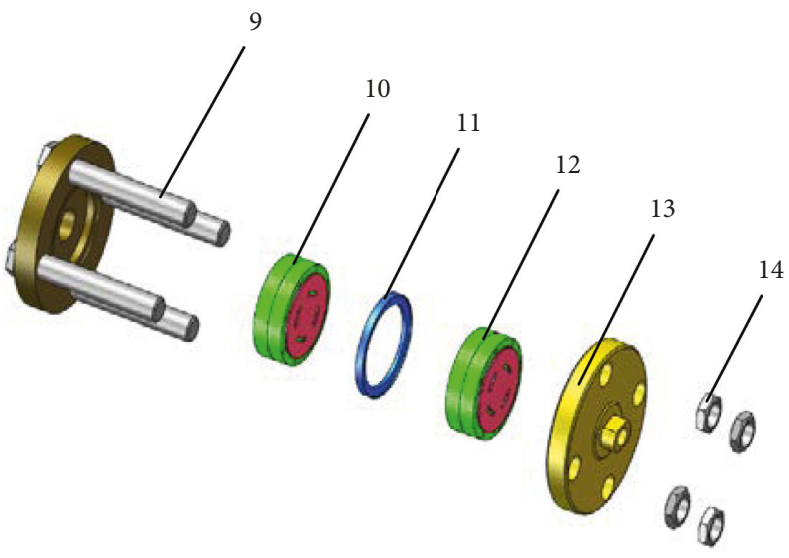

(b)

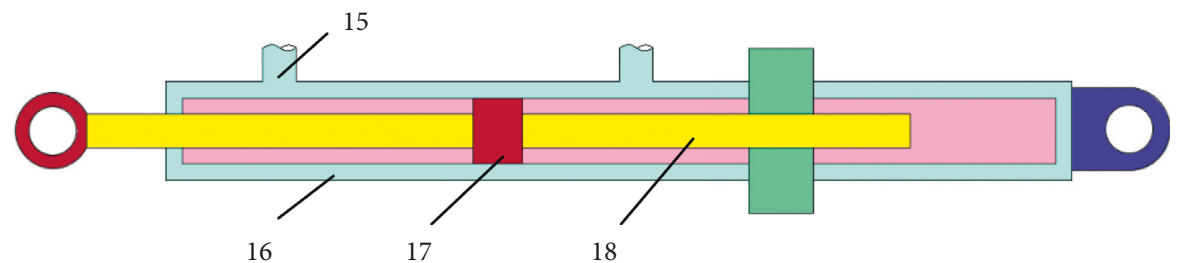

(c)

Figure 40: Illustration of the MR valve component. (a) Module's cross-sectional view, (b) exploded view, and (c) schematic of double rod hydraulic cylinder. 1 coil bobbin; 2 , valve casing; 3 , disc holder; 4 , orifice core; 5 , disc core; 6 , bolt $2 \mathrm{~mm}$; 7, fluid gap; 8, coil; 9, bolt 6 mm; 10 , 1st stage module; 11, flange; 12 , 2nd stage module; 13, cap; 14, nut; 15, double inlet port; 16, monotube cylinder; 17, piston; 18, rod [100].

magnetic field will be very high. Without magnetic field, a smaller damping force is also obtained by an additional flowthrough hole with proper diameters in a piston. Moreover, such an additional flow will effectively limit very large damping force if flow in circumferential channels and a control strategy are just failed.
Overall, a damper shown in Figure 42 [101] can generate wide damping range and greatly enhance utilization of the magnetic field. However, the arrangement of damping channels inside a damper also brings obvious limitations in manufacturing and assembling, heat dissipation, expansibility without redesign, etc. 


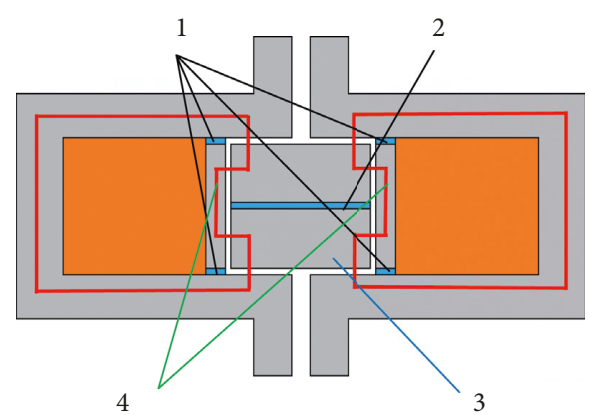

(a)

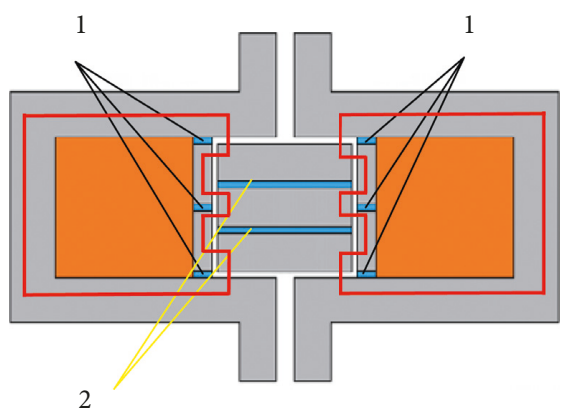

(b)

FIGURE 41: Schematic view of MR valve with serpentine-flux path. (a) One-step serpentine-flux valve. (b) Two-steps serpentine-flux valve. 1, nonmagnetic rings; 2, nonmagnetic disks; 3 , core; 4, coil separator [80].

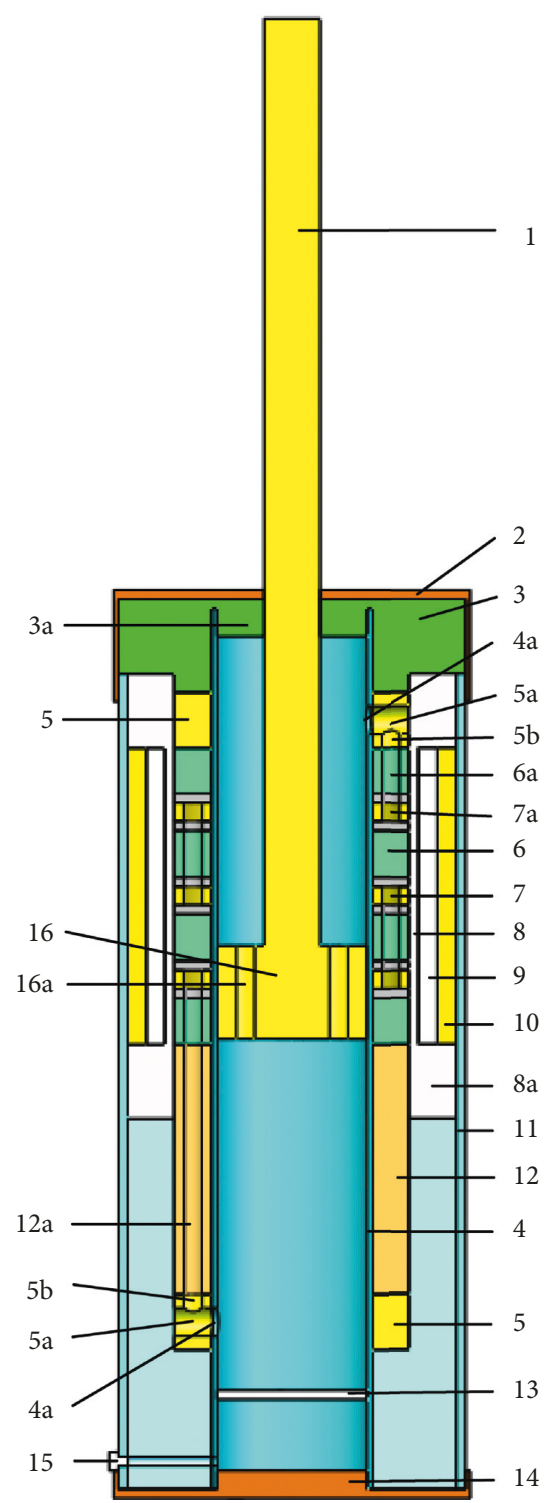

(a)

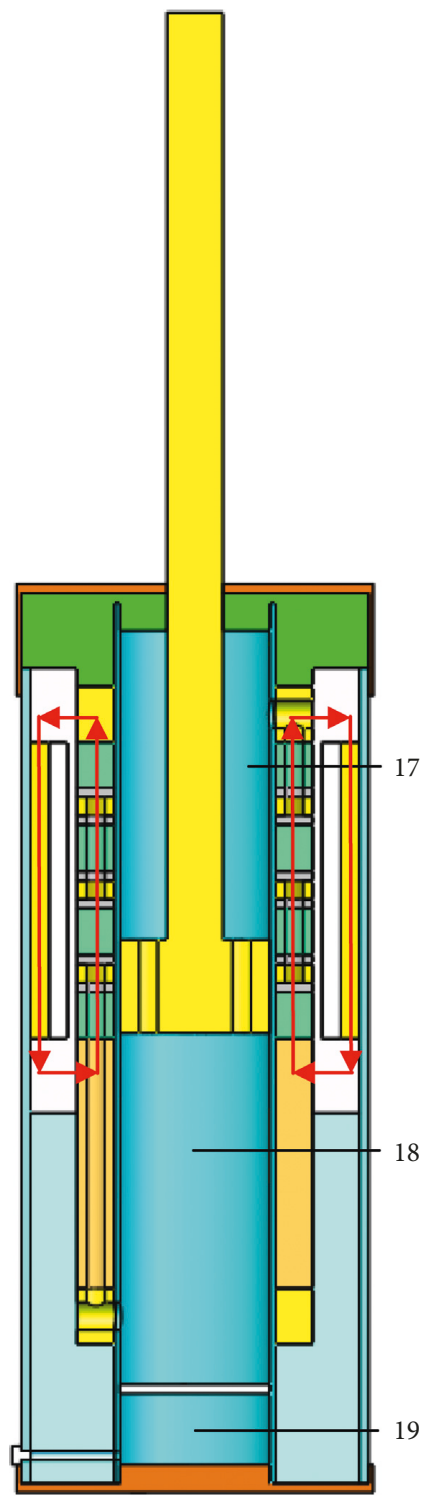

(b)

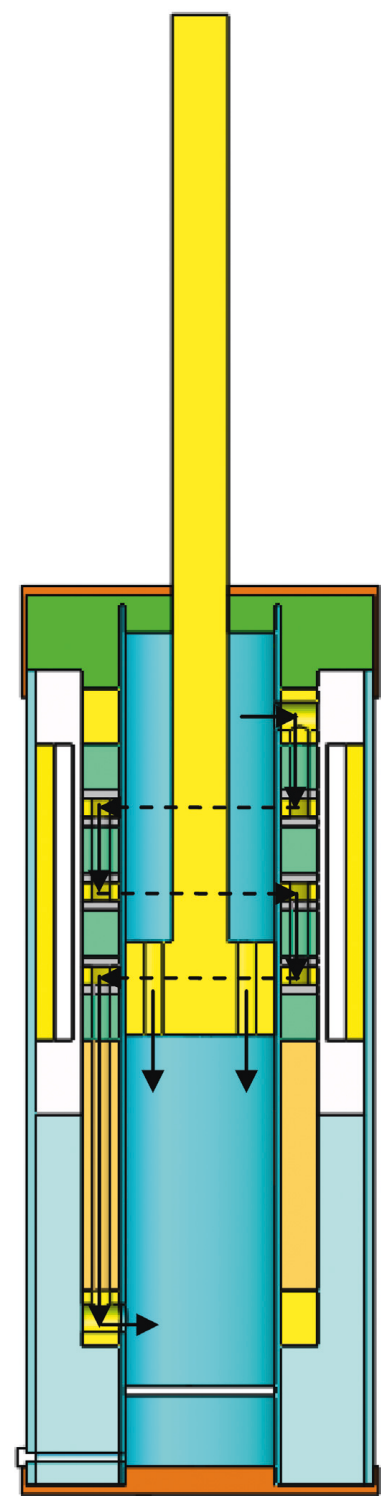

(c)

FIGURE 42: Schematic diagram of MR damper based on multistage circumferential flow mode: 1, piston rod; 2, upper end plate; 3, upper retaining plate; $3 \mathrm{a}$, sealing and rod guiding; 4 , inner tube; $4 \mathrm{a}$, the first hole; 5 , chuck; $5 \mathrm{a}$, the second flow hole; $5 \mathrm{~b}$, the third flow hole; 6 , ferromagnetic core; $6 \mathrm{a}$, the fourth hole; 7 , circumferential channel; $7 \mathrm{a}$, the fifth flow hole; 8 , outer tube; $8 \mathrm{a}$, end magnetic core; 9 , electromagnetic coil; 10, magnetic cylinder; 11, housing; 12, supporting cylinder; 12a, the sixth flow hole; 13 , the moveable wall; 14 , lower end plate; 15, nozzle; 16, piston; 16a, through-hole; 17, rebound chamber; 18, compression chamber; 19, gas chamber [101]. 
Considering advantages of a circumferential flow mode and overcoming defects of the arrangement inside a damper, a novel damper was also invented by Yuan [78]. Portrayed in Figure 43 [78], this damper contains a damper body and an external valve. The damper body mainly includes an inner cylinder, an intermediate cylinder, an outer cylinder, a piston valve assembly, a foot valve, guiding components, and a piston rod, all of which are the same as those of passive dampers. Significant difference occurs in operation way of the piston valve assembly and the foot valve. In a traditional damper, a tension valve in the piston valve must be easy to open so that the fluid will be flowed through it in a rebound stage and the compression valve of the foot valve is also opened under enough pressures in the compression stage. However, two valves will not be opened under a normal pressure, mainly providing a function of overloading protection. Other two valves, a flow valve in a piston and a compensation valve of the foot valve, are readily opened. All of the valves in the piston and foot valve are one-way valves, and the structures are almost the same as those of passive dampers. Under a rebound stage, the fluid in the rebound chamber is first flowed into an intermediate chamber by a through-hole of the inner cylinder. The fluid from the intermediate chamber is then returned to the compression chamber through an external valve, the reservoir, and a compensation valve. In a stage of compression, the fluid in the compression chamber can be easily entered into a rebound chamber by a flow valve, and the fluid is then flowed through a through-hole, the intermediate chamber, an external valve, and the reservoir.

Adopting these valves and a three-cylinder structure, the flow with a single direction is obtained so that most of fluid will be passed through an external valve. Therefore, active adjustment for viscosity can be achieved in an external valve. As is shown in the enlarged diagram of the external valve, two-stage circumferential channels are utilized, and the flow in circumferential channels is the same as that mentioned in Figure 42 [101]. Circumferential channels are arranged on the inner wall of a magnetic isolating element, and a coil is located at the outer wall of the magnetic isolating element. Shown as red dash lines, magnetic flux paths can be achieved based on materials with suitable magnetic permeability, especially adopting magnetic isolating material in the inner and outer walls of circumferential channels. Combining such a magnetic field and the flow direction, the fluid in circumferential channels is just controlled by the magnetic field, and the distribution of magnetic field intensity is almost uniform in a circumferential channel. In a very small external valve, an effective length of a damping channel can be expanded greatly, and the maximum damping force will be very large, especially adopting more-stage channels. Increasing height of circumferential channels gets even smaller damping force without magnetic field. Therefore, a damping range will be quite wide.

In addition to such a main advantage, the damping force in a compression stage can be lowered to some extent because of a flow valve in the piston valve, thus providing an asymmetrical damping force. The heat generated by a coil has little effect in MRF, and a long reservoir in the outer side is helpful to dissipate heat. Unscrewing the adjusting device, the number of circumferential channels can be added or reduced. Therefore, the damper is possible to extend without any redesign, and it can be matched in more fields of vibration control.

The cost of the damper is mainly determined by MRF, and the miniature external valve has little influence in cost. Such a valve can be flexibly arranged on the outer wall of the damper body, and it can be applied in a limited space. Moreover, the coil turns, magnetic flux density, and energy consumption will be reduced as long as the damping force is not particularly large.

Almost all of the expected advantages are concentrated on this damper such as the wide damping range, high utilization of magnetic field, asymmetry, extensibility, extensively matching ability, relatively low cost, small volume, excellent heat dissipation, weak excitation of magnetic field, low energy consumption, etc. Therefore, a damper with multistage circumferential flow mode in a bypass valve may represent one of further developments.

However, before entering an external valve, the fluid must be flowed through a long path. Response time of this damper will be increased to some extent. Only depending on one bypass valve, it does not contribute to fast switching and reducing its working load.

Considering these problems, the newest damper with two external valves is designed by Yuan this year [79]. As is mentioned in Figure 44 [79], the intermediate cylinder is divided into two segments, and each one is matched with the inner cylinder so that two intermediate chambers can be obtained. The upper and lower ones are, respectively, connected to the first and second valves. A flow valve mentioned in Figure 43 [78] is cancelled, and another one-way valve with a compensation function is installed near the guiding assembly. Other three valves inside cylinders are the same as those of a damper mentioned in Figure 43 [78]. Owing to such a structure, fluid in a rebound chamber will be first flowed into the upper intermediate chamber, and it is then returned to the compression chamber through the first valve, the reservoir, and a compensation valve in the foot valve. Under a compression stage, the fluid in the compression chamber is flowed into the lower intermediate chamber. Further flowing through the second valve, the reservoir, and a compensation valve near the guiding assembly, the partial fluid is compensated to the rebound chamber.

Although the complexity and cost of this damper will be increased, the more advantages are also concentrated on it, especially achieving the independent and continuous control of damping force. It is confident that it may be an excellent damper representing a technical feature in future.

\section{Conclusion}

Reflecting through existing structures, the summary gives us insight into structural development in three technical routes, mainly considering positions and turns of coils, improvement in the magnetic circuit and innovative flow modes. Structural characteristics and their significant effects on performance and others can be followed that: 


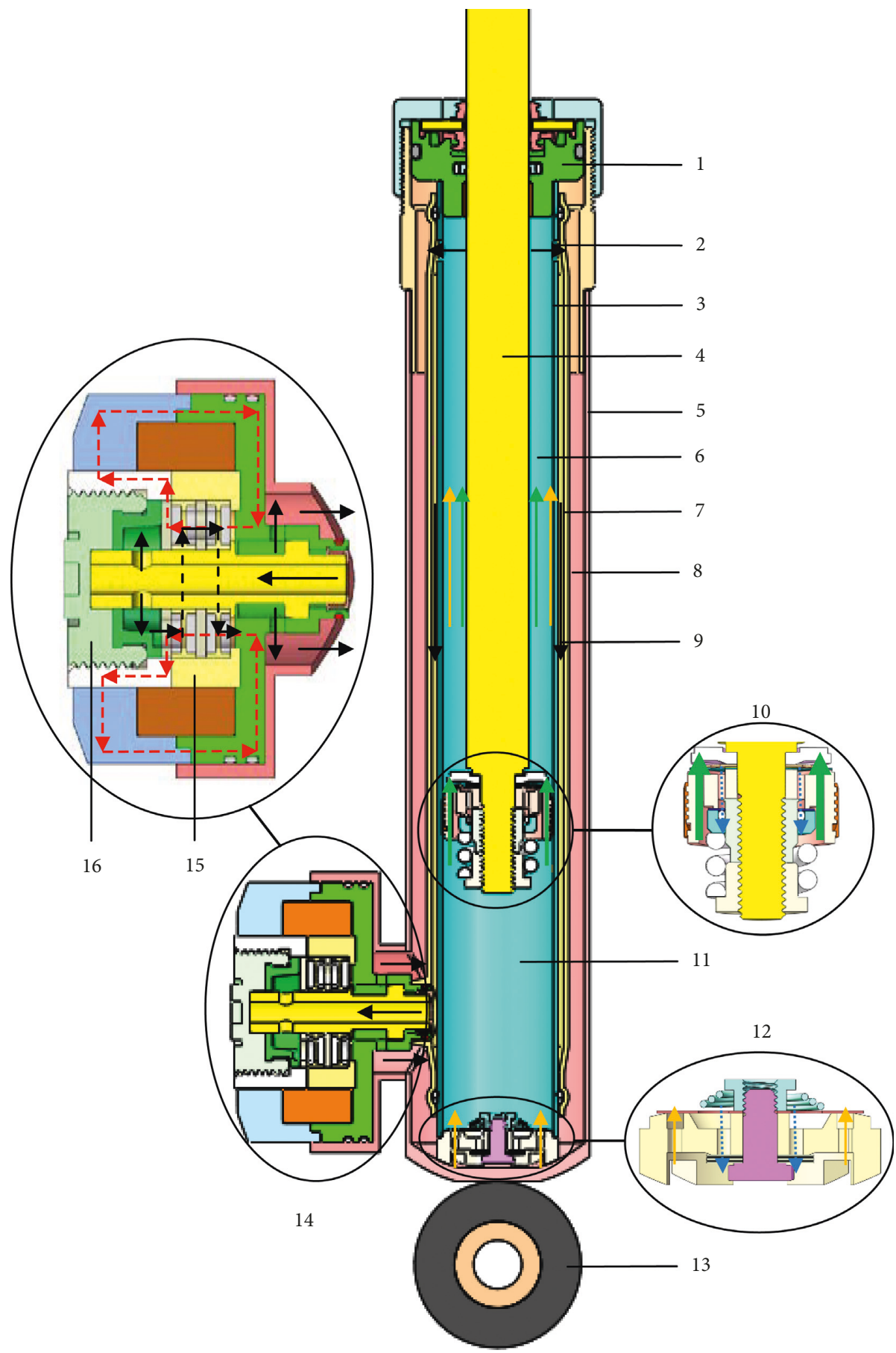

FIGURE 43: Schematic diagram of MR damper combining with a multistage circumferential flow mode in a bypass valve: 1 , guiding components; 2, through-hole; 3, main cylinder; 4, piston rod; 5, outer tube; 6 , rebound chamber; 7, intermediate tube; 8, reservoir; 9 , intermediate chamber; 10 , piston valve; 11, compression chamber; 12, foot valve; 13, rubber bushing; 14 , external valve; 15, magnetic isolating element; 16, adjusting device [78].

(1) Still controlling viscosity in a limited axial channel, the damping ranges, and force will be expanded to some extent due to different positions and turns of coils, improvement of special magnetic flux paths, and other methods. The limitations in the damping range and others cannot be completely overcome by such structural changes.
(2) Adopting other flow modes such as the radial and circumferential flow modes, a longer length of damping channels can be obtained. Especially combining radial or circumferential flow modes in a miniature external valve, more excellent performances can be achieved. Therefore, utilizing a novel flow mode in a miniature bypass valve may 


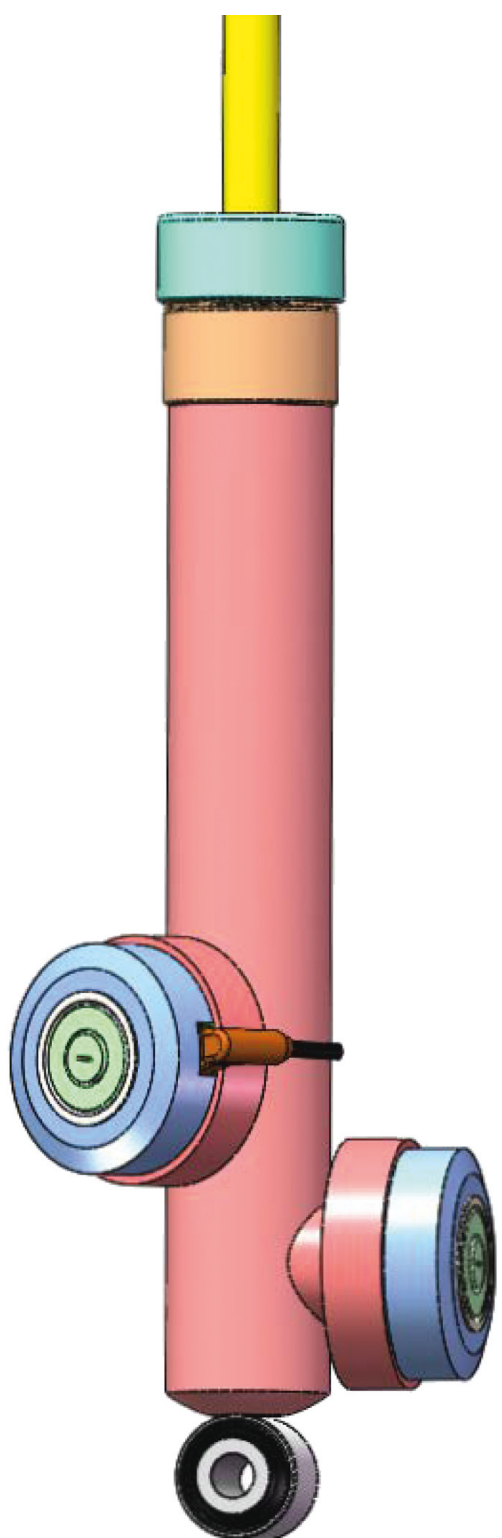

(a)

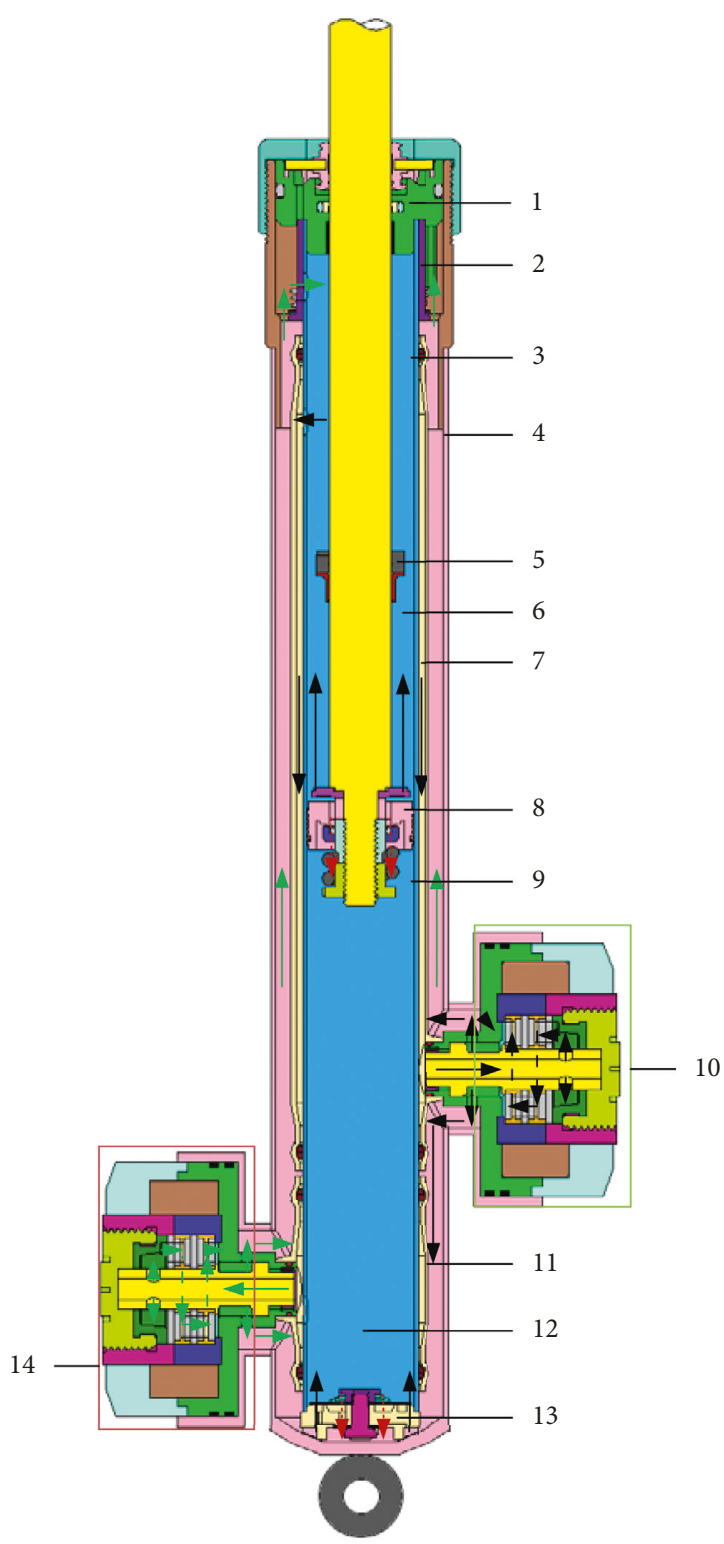

(b)

FIGURE 44: Schematic diagram and cross-sectional view of MR damper with controlling damping force independently for compression and rebound: 1 , guiding assembly; 2 , check valve assembly; 3 , piston rod; 4 , outer cylinder; 5 , buffer; 6 , rebound chamber; 7 , upper intermediate cylinder; 8, piston assembly; 9 , inner cylinder; 10, first valve for rebound; 11, lower intermediate cylinder; 12, compression chamber; 13, foot valve; 14 , second valve for compression [79].

represent the latest structural and one of future technologies.

(3) Overcoming the limitation in the application because of a high cost mainly determined by MRF, a future damper should be operated in a way that a novel flow mode, miniature bypass valves, and dual hydraulic systems are concentrated on it. A very small amount of MRF is utilized to regulate a flow channel of a conventional oil. Reducing the amount of MRF and a cost of itself, such excellent dampers will be widely accepted by more fields, thus promoting technical development further.

Overall, combining future requirements such as longer damping channel, high magnetic field utilization, larger damping range, weak magnetic field excitation, smaller volume, less energy consumption, better generality, and lower costs, the future damper will be anticipated.

\section{Conflicts of Interest}

The authors declare that there are no conflicts of interest regarding the publication of this paper.

\section{Acknowledgments}

The authors gratefully acknowledge that the partial research of external valves described in Figures 43 and 44 was sponsored by the National Natural Science Foundation of 
China (no. 51605149), and internal valves were compensated by an initiation Fund for Doctoral Research (no. BK201608) provided by Hubei University of Automotive Technology. The authors also thank that the work was mainly supported by an Innovation Fund Project (no. 2015XTZX0402) funded by Hubei Collaborative Innovation Center for Automotive Components Technology as well as Key Laboratory of Automotive Power Train and Electronics (Hubei University of Automotive Technology) and the Open Fund Project (no. ZDK1201604) sponsored by Key Laboratory of Automotive Power Train and Electronics (Hubei University of Automotive Technology).

\section{References}

[1] K. Kim and D. Jeon, "Vibration suppression in an MR fluid damper suspension system," Journal of Intelligent Material Systems and Structures, vol. 10, no. 10, pp. 779-786, 1999.

[2] J. C. Poynor, "Innovative designs for magneto-rheological dampers," Master's thesis, Virginia Polytechnic Institute and State University, Blacksburg, VA, USA, 2001.

[3] J. E. Lindler, G. A. Dimock, and N. M. Wereley, "Design of a magnetorheological automotive shock absorber," in Smart Structures and Integrated Systems 2000: Smart Structures and Integrated Systems, pp. 426-438, International Society for Optics and Photonics, Newport Beach, CA, USA, 2000.

[4] F. Gordaninejad and S. P. Kelso, "Magneto-rheological fluid shock absorbers for HMMWV," in Smart Structures and Materials 2000: Damping and Isolation, vol. 3989, pp. 266-274, International Society for Optics and Photonics, Newport Beach, CA, USA, 2000.

[5] H. Sodeyama, K. Suzuki, and K. Sunakoda, "Development of large capacity semi-active seismic damper using magnetorheological fluid," Journal of Pressure Vessel Technology, vol. 126, no. 1, pp. 105-109, 2004.

[6] M. Ahmadian and J. C. Poynor, "An evaluation of magneto rheological dampers for controlling gun recoil dynamics," Shock and Vibration, vol. 8, no. 3-4, pp. 147-155, 2001.

[7] A. Dobre, C. N. Andreescu, and C. Stan, "The influence of the current intensity on the damping characteristics for a magneto-rheological damper of passenger car," IOP Conference Series: Materials Science and Engineering, vol. 147, no. 1, article 012110, 2016.

[8] V. Paciello and A. Pietrosanto, "Magnetorheological dampers: a new approach of characterization," IEEE Transactions on Instrumentation and Measurement, vol. 60, no. 5, pp. 17181723, 2011.

[9] F. Gordaninejad, X. Wang, G. Hitchcock, K. Bangrakulur, S. Ruan, and M. Siino, "Modular high-force seismic magneto-rheological fluid damper," Journal of Structural Engineering, vol. 136, no. 2, pp. 135-143, 2010.

[10] H. J. Jung, B. F. Sodeyama, Y. Q. Ni et al., "State-of-the-art of semiactive control systems using MR fluid dampers in civil engineering applications," Structural Engineering and Mechanics, vol. 17, no. 3-4, pp. 493-526, 2004.

[11] B. F. Spencer and S. Nagarajaiah, "State of the art of structural control," Journal of structural engineering, vol. 129, no. 7, pp. 845-856, 2003.

[12] H.-C. Kim, Y.-J. Shin, W. You, K. C. Jung, J.-S. Oh, and S.-B. Choi, "A ride quality evaluation of a semi-active railway vehicle suspension system with MR damper: railway field tests," Proceedings of the Institution of Mechanical Engineers,
Part F: Journal of Rail and Rapid Transit, vol. 231, no. 3, pp. 306-316, 2017.

[13] Y. K. Lau and W. H. Liao, "Design and analysis of magnetorheological dampers for train suspension," Proceedings of the Institution of Mechanical Engineers, Part F: Journal of Rail and Rapid Transit, vol. 219, no. 4, pp. 261-276, 2005.

[14] D. H. Wang and W. H. Liao, "Semi-active suspension systems for railway vehicles using magnetorheological dampers. Part I: system integration and modelling," Vehicle System Dynamics, vol. 47, no. 11, pp. 1305-1325, 2009.

[15] J. D. Carlson, W. Matthis, and J. R. Toscano, "Smart prosthetics based on magnetorheological fluids," Smart Structures and Materials 2001: Industrial and Commercial Applications of Smart Structures Technologies, vol. 4332, pp. 308-317, International Society for Optics and Photonics, Bellingham, WA, USA, June 2001.

[16] G. Aydar, A new magneto-rheological fluid (MRF) washing machine damper and a novel two-way-controllable MRF valve, Ph.D. dissertation, University of Nevada, Reno, NV, USA, 2007.

[17] C. Spelta, F. Previdi, S. M. Savaresi, G. Fraternale, and N. Gaudiano, "Control of magnetorheological dampers for vibration reduction in a washing machine," Mechatronics, vol. 19, no. 3, pp. 410-421, 2009.

[18] S. Dutta and S. B. Choi, "A nonlinear kinematic and dynamic modeling of Macpherson suspension systems with a magneto-rheological damper," Smart Materials and Structures, vol. 25, no. 3, article 035003, 2016.

[19] B. Ebrahimi, Development of hybrid electromagnetic dampers for vehicle suspension systems, Ph.D. dissertation, University of Waterloo, Waterloo, Canada, 2009.

[20] B. Heißing and M. Ersoy, Chassis Handbook, Springer Science \& Business Media, Berlin, Germany, 2010.

[21] J. H. Park, W. H. Kim, C. S. Shin et al., "A comparative work on vibration control of a quarter car suspension system with two different magneto-rheological dampers," Smart Materials and Structures, vol. 26, no. 1, article 015009, 2016.

[22] D. Y. Lee, Y. J. Nam, R. Yamane et al., "Performance evaluation on vibration control of MR landing gear," Journal of Physics: Conference Series, vol. 149, article 012068, 2009.

[23] M. Khani, Magneto-rheological (MR) damper for landing gear system, Ph.D. dissertation, Concordia University, Montreal, Canada, 2010.

[24] S.-B. Choi, M.-H. Nam, and B.-K. Lee, "Vibration control of a MR seat damper for commercial vehicles," Journal of Intelligent Materials Systems and Structures, vol. 11, no. 12, pp. 936-944, 2000.

[25] H. Du, W. Li, and N. Zhang, "Semi-active variable stiffness vibration control of vehicle seat suspension using an MR elastomer isolator," Smart Materials and Structures, vol. 20, no. 10, article 105003, 2011.

[26] A. Milecki and M. Hauke, "Application of magnetorheological fluid in industrial shock absorbers," Mechanical Systems and Signal Processing, vol. 28, pp. 528-541, 2012.

[27] N. M. Wereley, W. Hu, C. S. Kothera et al., "Magnetorheological fluid elastic lag damper for helicopter rotors," US Patent Application No. 8,413,772, 2013.

[28] C. Guo, X. Gong, L. Zong, C. Peng, and S. Xuan, "Twin-tubeand bypass-containing magneto-rheological damper for use in railway vehicles," Proceedings of the Institution of $\mathrm{Me}$ chanical Engineers, Part F: Journal of Rail and Rapid Transit, vol. 229, no. 1, pp. 48-57, 2015. 
[29] D. H. Wang and W. H. Liao, "Magnetorheological fluid dampers: a review of parametric modelling," Smart materials and Structures, vol. 20, no. 2, article 023001, 2011.

[30] M. Ashtiani, S. H. Hashemabadi, and A. Ghaffari, "A review on the magnetorheological fluid preparation and stabilization," Journal of Magnetism and Magnetic Materials, vol. 374, pp. 716-730, 2015.

[31] J. C. Dixon, The Shock Absorber Handbook, John Wiley \& Sons, London, UK, 2nd edition, 2008.

[32] J. Goldasz and B. Sapiński, Insight into Magnetorheological Shock Absorbers, Springer Science \& Business Media, Basel, Switzerland, 2015.

[33] M. Unsal, Semi-active vibration control of a parallel platform mechanism using magnetorheological damping, Ph.D. thesis, University of Florida, Gainesville, FL, USA, 2006.

[34] X. Zhu, X. Jing, and L. Cheng, "Magnetorheological fluid dampers: a review on structure design and analysis," Journal of Intelligent Material Systems and Structures, vol. 23, no. 8, pp. 839-873, 2012.

[35] A. Y. Abd Fatah, S. A. Mazlan, T. Koga, H. Zamzuri, and F. Imaduddin, "A review of design and modeling of magnetorheological valve," International Journal of Modern Physics B, vol. 29, no. 4, article 1530004, 2015.

[36] F. D. Goncalves, Characterizing the behavior of magnetorheological fluids at high velocities and high shear, Ph.D. dissertation, Virginia Polytechnic Institute and State University, Blacksburg, VA, USA, 2005.

[37] F. D. Goncalves, M. Ahmadian, and J. D. Carlson, "Investigating the magnetorheological effect at high flow velocities," Smart Materials and Structures, vol. 15, no. 1, pp. 75-85, 2005.

[38] G. Hu, F. Liu, Z. Xie et al., "Design, analysis, and experimental evaluation of a double coil magnetorheological fluid damper," Shock and Vibration, vol. 2016, Article ID 4184726, 12 pages, 2015-2016.

[39] Y. K. Lau and H. Liao, "Pressurized magnetorheological fluid dampers," US Patent Application No. 11/460,728, 2007.

[40] G. Yang, B. F. Spencer, J. D. Carlson, and M. K. Sain, "Largescale MR fluid dampers: modeling and dynamic performance considerations," Engineering Structures, vol. 24, no. 3, pp. 309-312, 2002.

[41] J. Zheng, Z. Li, J. Koo, and J. Wang, "Magnetic circuit design and multiphysics analysis of a novel MR damper for applications under high velocity," Advances in Mechanical Engineering, vol. 6, article 402501, 2014.

[42] S. Sassi, K. Cherif, L. Mezghani, M. Thomas, and A. Kotrane, "An innovative magnetorheological damper for automotive suspension: from design to experimental characterization," Smart Materials and Structures, vol. 14, no. 4, pp. 811-822, 2005.

[43] J. Goldasz, "Theoretical study of a twin-tube magnetorheological damper concept," Journal of Theoretical and Applied Mechanics, vol. 53, no. 4, pp. 885-894, 2015.

[44] H. Gavin, J. Hoagg, and M. Dobossy, "Optimal design of MR dampers," in Proceedings of U.S.-Japan Workshop on Smart Structures for Improved Seismic Performance in Urban Regions, pp. 225-236, Seattle, WA, USA, August 2001.

[45] K. H. Guo, Y. Liu, and B. X. Zhang, "Magnetorheogical fluid absorber," China Patent No. 201510213126.1, 2015.

[46] N. L. Wilson, N. M. Wereley, W. Hu et al., "Analysis of a magnetorheological damper incorporating temperature dependence," International Journal of Vehicle Design, vol. 63, no. 2-3, pp. 137-158, 2013.
[47] S. P. Kelso, "Experimental characterization of commercially practical magnetorheological fluid damper technology," in Smart Structures and Materials 2001: Industrial and Commercial Applications of Smart Structures Technologies, pp. 292-299, International Society for Optics and Photonics, Bellingham, WA, USA, 2001.

[48] I. I. M. Yazid, S. A. Mazlan, H. Zamzuri, M. J. Mughni, and S. Chuprat, "Parameters consideration in designing a magnetorheological damper," Key Engineering Materials, vol. 543, pp. 487-490, 2013.

[49] T. W. Nehl and A. A. Alexandridis, "Magnetorheological devices with permanent magnet field bias," US Patent Application No. 12/287,951, 2014.

[50] H. Boese and J. Ehrlich, "Performance of magnetorheological fluids in a novel damper with excellent fail-safe behavior," Journal of Intelligent Material Systems and Structures, vol. 21, no. 15, pp. 1537-1542, 2010.

[51] H. Bose, J. Ehrlich, P. Meneroud et al., "Magnetorheological force transmission device," US Patent Application No. 8/ 205,728, 2012.

[52] Y. S. Koh, "Double-tube shock absorber using a hydraulic fluid and a magnetorheological fluid," US Patent Application No. 6,360,856, 2002.

[53] E. L. Jensen, M. W. Hurtt, D. A. Shal et al., "Magnetorheological damper," European Patent No. 1,903,252A1, 2008.

[54] J. D. Carlson and M. J. Chrzan, "Magnetorheological fluid dampers," US Patent Application No. 5,277,281, 1994.

[55] R. Noakley, "Twin-tube magnetorheological damper," European Patent No. EP1908985A1, 2008.

[56] A. L. Browne, J. C. Ulicny, C. S. Namuduri et al., "Bi-fold valve-type magnetorheological fluid energy absorbing device," US Patent Application No. 7,900,755, 2011.

[57] K. H. Guo, X. J. Zhang, and G. Guo, "Magneto-rheological pump type variable-damping shock absorber," China Patent No. 201110342597.4, 2011.

[58] X. Zhang, Z. Li, K. Guo, F. Zheng, and Z. Wang, “A novel pumping magnetorheological damper: design, optimization, and evaluation," Journal of Intelligent Material Systems and Structures, vol. 28, no. 17, pp. 2339-2348, 2017.

[59] M. Mao, W. Hu, Y.-T. Choi, and N. M. Wereley, "A magnetorheological damper with bifold valves for shock and vibration mitigation," Journal of Intelligent Material Systems and Structures, vol. 18, no. 12, pp. 1227-1232, 2007.

[60] P. C. Chen and N. M. Wereley, "Magnetorheological damper and energy dissipation method," US Patent Application No. 6,694,856, 2004.

[61] W. B. Facey, N. C. Rosenfeld, Y.-T. Choi, N. M. Wereley, S. B. Choi, and P. Chen, "Design and testing of a compact magnetorheological damper for high impulsive loads," International Journal of Modern Physics B, vol. 19, no. 07n09, pp. 1549-1555, 2005.

[62] X. J. Zhang, Y. X. Zhang, D. D. Wei et al., "Screw valve hole type magnetic rheologic vibration damper," China Patent No. 201320298897.1, 2013.

[63] R. Ahamed, M. M. Ferdaus, and Y. Li, "Advancement in energy harvesting magneto-rheological fluid damper: a review," Korea-Australia Rheology Journal, vol. 28, no. 4, pp. 355-379, 2016.

[64] X.-X. Bai, W. Hu, and N. M. Wereley, "Magnetorheological damper utilizing an inner bypass for ground vehicle suspensions," IEEE Transactions on Magnetics, vol. 49, no. 7, pp. 3422-3425, 2013. 
[65] H. Hong, S. Tang, Y. Sheng et al., "Magnetic circuit design and computation of a magnetorheological damper with exterior coil," in Proceedings of 2015 IEEE International Conference on Mechatronics and Automation (ICMA), pp. 60-64, Beijing, China, August 2015.

[66] S.-R. Hong, G. Wang, W. Hu, and N. M. Wereley, "Liquid spring shock absorber with controllable magnetorheological damping," Proceedings of the Institution of Mechanical Engineers, Part D: Journal of Automobile Engineering, vol. 220, no. 8, pp. 1019-1029, 2006.

[67] A. Fuchs, A. Rashid, Y. Liu, B. Kavlicoglu, H. Sahin, and F. Gordaninejad, "Compressible magnetorheological fluids," Journal of Applied Polymer Science, vol. 115, no. 6, pp. 3348-3356, 2010.

[68] Y.-J. Nam and M.-K. Park, "Performance evaluation of two different bypass-type MR shock dampers," Journal of Intelligent Material Systems and Structures, vol. 18, no. 7, pp. 707-717, 2007.

[69] E. Cook, W. Hu, and N. M. Wereley, "Magnetorheological bypass damper exploiting flow through a porous channel," Journal of Intelligent Material Systems and Structures, vol. 18, no. 12, pp. 1197-1203, 2007.

[70] W. Hu, E. Cook, and N. M. Wereley, "Energy absorber using a magnetorheological bypass valve filled with ferromagnetic beads," IEEE Transactions on Magnetics, vol. 43, no. 6, pp. 2695-2697, 2007.

[71] G. McLaughlin, W. Hu, and N. M. Wereley, "Advanced magnetorheological damper with a spiral channel bypass valve," Journal of Applied Physics, vol. 115, no. 17, article 17B532, 2014.

[72] G. H. Hitchcock, X. Wang, and F. Gordaninejad, "A new bypass magnetorheological fluid damper," Journal of $\mathrm{Vi}$ bration and Acoustics, vol. 129, no. 5, pp. 641-647, 2007.

[73] X. Wang, F. Gordaninejad, G. Hitchcock et al., "A new modular magneto-rheological fluid valve for large-scale seismic applications," in Smart Structures and Materials 2004: Damping and Isolation, pp. 226-237, International Society for Optics and Photonics, San Diego, CA, USA, 2004.

[74] F. Imaduddin, S. A. Mazlan, M. A. A. Rahman et al., "A high performance magnetorheological valve with a meandering flow path," Smart Materials and Structures, vol. 23, no. 6, article 065017, 2014.

[75] F. Imaduddin, S. A. Mazlan, H. Zamzuri, and I. I. M. Yazid, "Design and performance analysis of a compact magnetorheological valve with multiple annular and radial gaps," Journal of Intelligent Material Systems and Structures, vol. 26, no. 9, pp. 1038-1049, 2015.

[76] F. Yazid, S. A. Mazlan, M. H. Ubaidillah, M. H. Idris, and I. Idris, "Characterization and modeling of a new magnetorheological damper with meandering type valve using neuro-fuzzy," Journal of King Saud University-Science, vol. 29, no. 4, pp. 468-477, 2017.

[77] C. R. Liao, D. X. Zhao, L. Xie et al., "A design methodology for a magnetorheological fluid damper based on a multistage radial flow mode," Smart Materials and Structures, vol. 21, no. 8, article 085005, 2012.

[78] X. J. Yuan, T. Y. Tian, and H. T. Ling, "Combined type magnetorheological suspensions shock absorber," China Patent No. 201721412471.9, 2017.

[79] X. J. Yuan, T. Y. Tian, and H. T. Ling, "Magnetorheological fluid damper capable of independently and continuously adjusting and controlling restoring damping force and compression damping force," China Patent No. 201810042113.6, 2018.
[80] A. Fatah, S. A. Mazlan, T. Koga et al., "Design of magnetorheological valve using serpentine flux path method," International Journal of Applied Electromagnetics and Mechanics, vol. 50, no. 1, pp. 29-44, 2016.

[81] T. W. Nehl, A. A. Alexandridis, R. T. Foister et al., "Magnetorheological fluid-based device having a magnetorheological piston assembly," US Patent Application No. 12/ $011,663,2012$.

[82] M. Oliver, W. Kruckemeyer, and T. Bishop, "Magnetorheological piston with bypass valving," US Patent Application No. 20030000781 A, 2003.

[83] M. R. Potnuru, X. J. Wang, S. Mantripragada et al., "A compressible magneto-rheological fluid damper - liquid spring system," International Journal of Vehicle Design, vol. 63, no. 2-3, pp. 256-274, 2013.

[84] J. Goldasz, "Study of a magnetorheological fluid damper with multiple annular flow gaps," International Journal of Vehicle Design, vol. 62, no. 1, pp. 21-41, 2013.

[85] I. Lisenker, R. L. Hofmann, and M. W. Hurtt, "Magnetorheological piston and damper assembly," US Patent Application No. 10/339,504, 2005

[86] K. Saito and K. Nakamura, "Magnetorheological fluid damper," US Patent Application No. 20150129378 A1, 2015.

[87] J. W. Sohn, J. S. Oh, and S. B. Choi, "Design and novel type of a magnetorheological damper featuring piston bypass hole," Smart Materials and Structures, vol. 24, no. 3, article 035013, 2015.

[88] C. S. Namuduri, A. A. Alexandridis, J. Madak, and D. S. Rule, "Magnetorheological fluid damper with multiple annular flow gaps," US Patent Application No. 09/394,726, 2001.

[89] X. X. Bai, N. M. Wereley, Y. T. Choi et al., “A bi-annular-gap magnetorheological energy absorber for shock and vibration mitigation," in Active and Passive Smart Structures and Integrated Systems 2012, vol. 8341, p. 834123, International Society for Optics and Photonics, Bellingham, WA, USA, 2012.

[90] K. Kim, Z. Chen, D. Yu et al., "Design and experiments of a novel magneto-rheological damper featuring bifold flow mode," Smart Materials and Structures, vol. 25, no. 7, article 075004, 2016.

[91] G. Aydar, X. Wang, and F. Gordaninejad, "A novel two-waycontrollable magneto-rheological fluid damper," Smart Materials and Structures, vol. 19, no. 6, article 065024, 2010.

[92] C. R. Liao, H. B. Liu, H. H. Zhang et al., "Magnetorheological fluid vibration damper with ring-shaped external magnetic field generator," China Patent No. 200810069967. X, 2008.

[93] X. L. Gong and C. Y. Guo, "Double-cylinder by-pass type magnetorheological vibration damper," China Patent No. 200910144970.8, 2009.

[94] H. X. Ai, D. H. Wang, and W. H. Liao, "Design and modeling of a magnetorheological valve with both annular and radial flow paths," Journal of Intelligent Material Systems and Structures, vol. 17, no. 4, pp. 327-334, 2006.

[95] Q.-H. Nguyen, Y.-M. Han, S.-B. Choi, and N. M. Wereley, "Geometry optimization of MR valves constrained in a specific volume using the finite element method," Smart Materials and Structures, vol. 16, no. 6, pp. 2242-2252, 2007.

[96] Q. H. Nguyen, S. B. Choi, and N. M. Wereley, "Optimal design of magneto-rheological valves via a finite element method considering control energy and a time constant," Smart Materials and Structures, vol. 17, no. 2, article 025024, 2008. 
[97] D. H. Wang, H. X. Ai, and W. H. Liao, "A magnetorheological valve with both annular and radial fluid flow resistance gaps," Smart Materials and Structures, vol. 18, no. 11, article 115001, 2009.

[98] X.-X. Bai, D.-H. Wang, and H. Fu, "Principle, modeling, and testing of an annular-radial-duct magnetorheological damper," Sensors and Actuators A: Physical, vol. 201, pp. 302-309, 2013.

[99] G. Hu, M. Liao, and W. Li, "Analysis of a compact annularradial-orifice flow magnetorheological valve and evaluation of its performance," Journal of Intelligent Material Systems and Structures, vol. 28, no. 10, pp. 1322-1333, 2017.

[100] B. Ichwan, S. A. Mazlan, F. Imaduddin et al., "Development of a modular MR valve using meandering flow path structure," Smart Materials and Structures, vol. 25, no. 3, article 037001, 2016.

[101] X. J. Yuan, “Automobile magneto-rheological absorber based on multistage circumferential flow mode," China Patent No. 201310498187.8, 2013. 


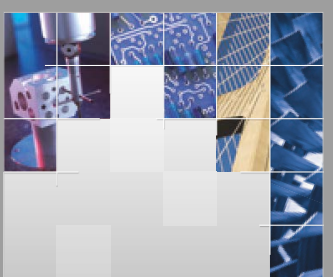

\section{Enfincering}
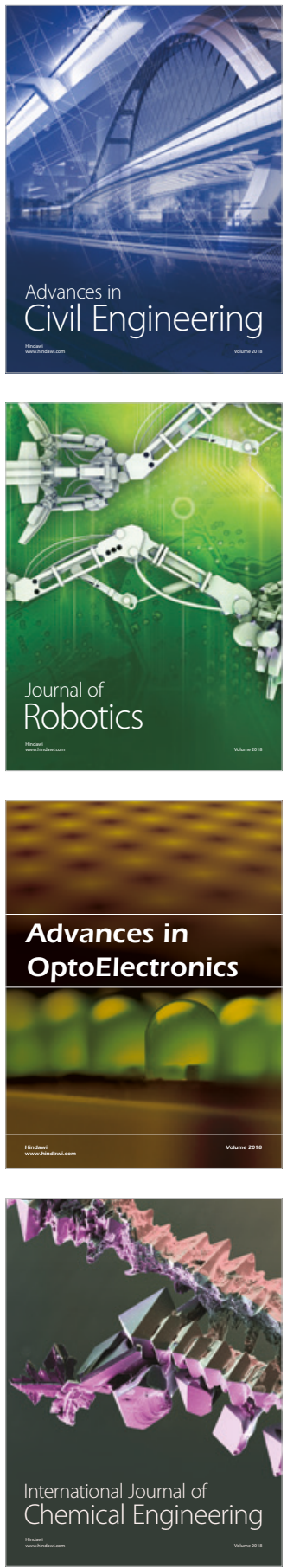

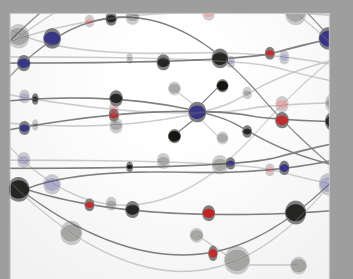

\section{Rotating \\ Machinery}

The Scientific World Journal

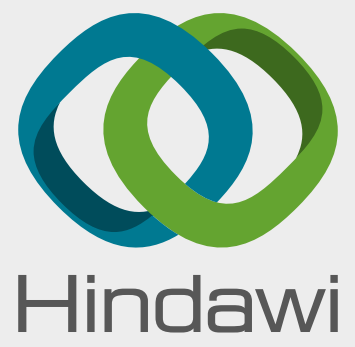

Submit your manuscripts at

www.hindawi.com
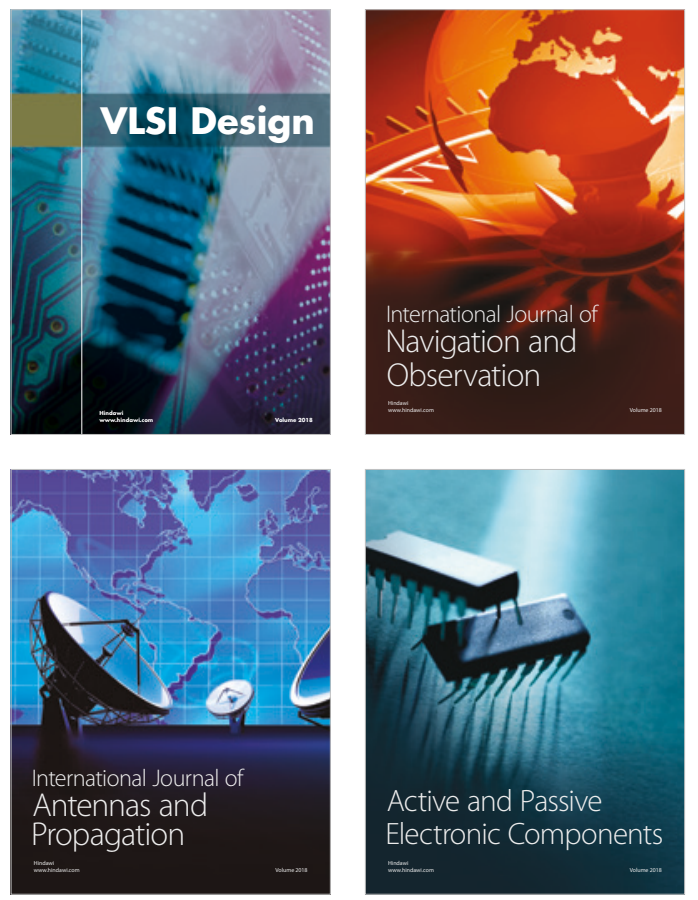
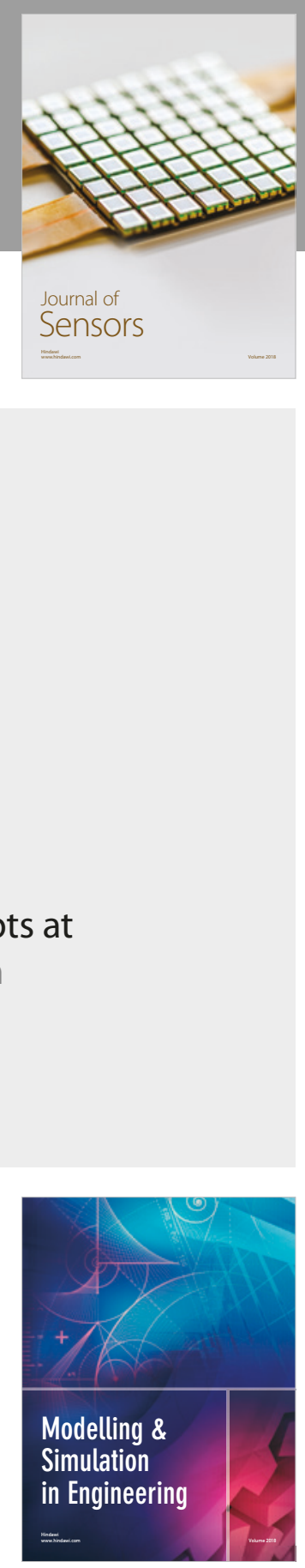

\section{Advances \\ Multimedia}
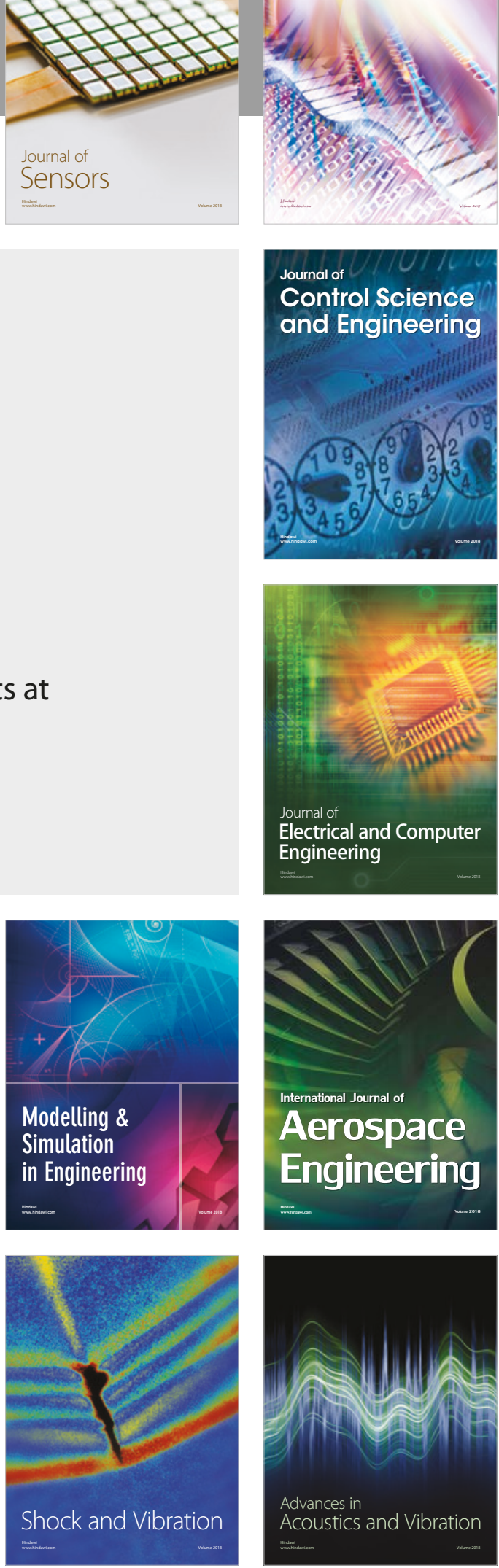